\title{
Evasão no setor público: estudo de caso da carreira dos especialistas em políticas públicas e gestão governamental no Estado de Minas Gerais $^{1}$
}

\author{
Rutila Maria Soares Gazzinelli Cruz \\ Fundação João Pinheiro - Belo Horizonte - MG, Brasil
}

\section{Claudio Burian Wanderley}

Fundação João Pinheiro - Belo Horizonte - MG, Brasil

Este artigo aborda a evasão na carreira de Especialista em Políticas Públicas e Gestão Governamental (EPPGG) no Governo do Estado de Minas Gerais. Seu objetivo principal é investigar as causas da evasão, conhecer em que condições ela ocorre e para onde se direcionam os recursos humanos que dela se desligaram. Apoia-se em pesquisa empírica realizada junto aos ex-integrantes da carreira, explorando os aspectos relacionados ao momento do desligamento, aos condicionantes para sua ocorrência, à relação com a experiência profissional e à direção tomada após a evasão. Foram obtidas 94 respostas de ex-servidores evadidos. A evasão tende a ocorrer logo nos primeiros anos da vida profissional, após o estágio probatório. Caso a saída ocorra antes desse prazo, o ex-servidor deve ressarcir o Estado o custo de seu treinamento. Os evadidos tendem a ganhar mais fora da carreira, a buscar também uma segunda graduação, em sua maioria em Direito, e a realocar-se no próprio serviço público. Apenas uma pequena parte se realoca no setor privado ou no terceiro setor. Como em outros estudos, a insatisfação salarial, e não com o próprio trabalho, parece ser a principal razão para a evasão.

Palavras-chave: administração pública em Minas Gerais, Especialista em Políticas Públicas e Gestão Governamental, evasão.

DOI: https://doi.org/10.21874/rsp.v71i3.3951 | E- ISSN: 2357-8017

[Artigo recebido em 10 de julho de 2019 e aceito em 22 de janeiro de 2020.]

${ }^{1}$ Parte integrante da Fundação João Pinheiro (2019), pesquisa financiada pela Fundação de Amparo à Pesquisa de Minas Gerais, Fapemig, edital 01/2015. 


\section{Evasión en el sector público: un estudio de caso de la carrera de especialistas en políticas públicas y gestión gubernamental en el estado de Minas Gerais}

Este artículo analiza la evasión en la carrera de Especialista en Políticas Públicas y Gestión Gubernamental (EPPGG) en el estado de Minas Gerais. Su objetivo principal es comprender las razones por las cuales ocurren estas evasiones, las características básicas de los evadidos y sus respectivos destinos profesionales. El trabajo se apoya en una investigación empírica realizada con los antiguos miembros de la carrera, donde se analizan los aspectos relacionados con el momento de la desconexión, las condiciones de su surgimiento, la relación con la experiencia profesional y la dirección tomada después de evadirse. Obtuvimos 94 respuestas a nuestra encuesta. La evasión tendería a ocurrir en los primeros años de trabajo. Caso el servidor deje el gobierno antes de tres años, debe de reembolsar al Estado por su capacitación. Los evadidos tienden a ganar más en la carrera, y también tienden a buscar una segunda titulación (la mayoría en derecho), así como a reubicarse en el propio servicio público. Al igual que en otros estudios, la insatisfacción salarial (y no con el trabajo en sí) parece ser la principal razón para la evasión.

Palabras clave: administración pública en Minas Gerais, Especialista en Políticas Públicas y Gestión Gubernamental, evasión.

\section{Evasion in the public sector: a case study of the career of specialists in public policies and government management in the state of Minas Gerais}

This research intends to discuss employee turnover in the Minas Gerais Public Policy and Government Management Specialist career (EPPGG). Its main objective is to understand the reasons why these evasions occur, the main characteristics of the evaded and their professional destiny. To do so, an empirical research was carried out with these career former members, exploring the reasons for this evasion, the conditions for its occurrence, the relation with the professional experience and the direction taken after it. We were able to get 94 answers for our questionnaire. The turnover tends to occur early in the working years. If the worker leaves the government before three years, he should pay the government back for his training. The evaders would tend to earn more out than in the abandoned career. They would also tend to seek a second college degree (most in law school). They also tend to relocate themselves in the public service (not in the private or in the third sectors). As in other studies, wage dissatisfaction seems to be the main reason for avoidance and not with work itself.

Key words: public management, Public Policies and Government Management Specialist, turnover. 


\section{Introdução}

A evasão da mão de obra é um problema sério para qualquer organização, porque pode revelar-se muito cara. A necessidade de se fazer novo processo de seleção, o que inevitavelmente sempre pode gerar resultados adversos, juntamente com o treinamento do novo contratado, faz com que essa reposição não custe pouco. Essas repercussões são ainda maiores no setor público, dadas as amarras normativas às quais ele está sujeito e à especificidade laboral que muitas vezes requer. Essas taxas de evasão têm sido crescentes nas últimas décadas em diversos países, tanto em nível federal quanto em níveis subnacionais.

As minorias, os mais jovens e os de maior nível de escolaridade são aqueles que tendem a se evadir mais de seus empregos. Não existem diferenças relativas ao gênero (BRIGHT, 2008). Empregados mais velhos, com mais tempo na organização, com maiores salários e com cargos de gerência tendem a se evadir menos que os demais (MoYNIHAN; LANDUYT, 2008; SELDEN; MOYNIHAN, 2000). Esses resultados, entretanto, são controversos. Exatamente devido à maior dificuldade de ingresso, as minorias (particularmente os negros e as pessoas provenientes de classes sociais mais desfavorecidas) se esforçam mais para continuar na carreira e, portanto, não se evadirem (FJP, 2019).

As taxas de evasão também são pró-cíclicas, ou seja, tendem a ser maiores quando a economia está crescendo, e decaem quando a economia se encontra em recessão.

No Brasil e em Minas Gerais, isso também parece ocorrer. Este texto tem por objetivo analisar a evasão na carreira de Especialista em Políticas Públicas e Gestão Governamental (EPPGG) no Estado de Minas Gerais. Através de pesquisa empírica realizada junto aos ex-integrantes da carreira, exploraram-se os aspectos relacionados ao momento do desligamento, aos condicionantes para sua ocorrência, à relação com a experiência profissional e à direção tomada após a evasão. Para tanto, dividiu-se este artigo em cinco seções. A seguir, faz-se uma revisão bibliográfica desse tema. Posteriormente, faz-se uma descrição da carreira juntamente com as principais características dos servidores atualmente na ativa. Descrevem-se, posteriormente, os resultados encontrados relativos aos evadidos. Por fim, fazem-se as conclusões tradicionais. 


\section{Motivação relativa ao setor público}

Para se entender a evasão de determinado emprego, deve-se entender a satisfação proporcionada por esse emprego ao trabalhador. Essa satisfação é relacionada tanto com as expectativas quanto com as necessidades de cada agente específico.

Podem-se citar dois grandes grupos de fatores determinantes da satisfação. Por um lado, existem fatores extrínsecos como a remuneração, a segurança e a saúde no trabalho, entre outros. Por outro, existem fatores intrínsecos relacionados à própria realização do agente em seu trabalho, como o prazer e a identificação com o mesmo, o desenvolvimento pessoal e profissional permitido e o status gerado, entre outros (KLEIN; MASCARENHAS, 2016).

Normalmente, a taxa de evasão é negativamente correlacionada com essa satisfação. A insatisfação no trabalho é indicador da intenção de deixar o emprego. Enquanto 4,3\% dos trabalhadores satisfeitos têm intenção de deixar o emprego, 54,2\% daqueles insatisfeitos apresentam a mesma característica (CAILLIER, 2013). No caso do setor público, apesar de a satisfação estar mais relacionada com os fatores intrínsecos citados, a evasão é mais determinada pela remuneração (KLEIN; MASCARENHAS, 2016).

Testes empíricos mostram uma grande satisfação com o trabalho no setor público americano em todos os níveis de governo (DESANTIS; DURST, 1996; ELLICKSON, 2002; KAMDROM, 2005). Uma explicação para isso são as recompensas não-monetárias relativas ao trabalho, ou seja, as boas relações com os colegas, as oportunidades de promoção, o desenvolvimento profissional e as técnicas de gerência mais participativas (ou seja, os fatores intrínsecos citados).

O que se chama de motivação relativa ao serviço público (PSM em inglês - public service motivation) também importa. Isso se refere ao sentimento altruísta de ajudar os outros que, supostamente, também incentiva os servidores públicos. Assim, programas de motivação no serviço público devem buscar alavancar o PSM dos servidores. Isso também contribui para fazer um melhor matching - melhor seleção dos potenciais dos servidores públicos. Ajuda a selecionar melhor aqueles trabalhadores que efetivamente 
apresentem maior perfil de serviço público, nesse caso, aqueles com maior sentimento de solidariedade em relação às outras pessoas.

Uma medida comumente aceita de PSM é baseada em questionário de 24 itens de Perry (1996). Esse nível de congruência indivíduo-organização também pode ser acessado de forma direta, perguntando aos próprios empregados (utilizando uma escala de Likert)². A literatura empírica, entretanto, não é conclusiva. A PSM se relaciona positivamente com a satisfação no emprego e, negativamente, com a intenção de deixá-lo (NAFF; CRUM, 1999; SCOTT; PANDEY, 2005). Por sua vez, enquanto a intenção de deixar o emprego relaciona-se negativamente com o tempo de permanência na organização (MOYNIHAN; PANDEY, 2007), o tempo de permanência na organização relaciona-se negativamente com a satisfação no trabalho (KAMDRom, 2005; NAFF; CRUM, 1999). Ou seja, o aumento do tempo de permanência no emprego levaria tanto à diminuição da satisfação no trabalho quanto à intenção de deixá-lo, o que seria contraditório a princípio.

Essa suposta incongruência pode ser explicada através da incompatibilidade do agente pesquisado com a organização. Um alto nível de PSM em organização não adequada levaria à desmotivação e evasão. Caso esse alto nível de PSM atraia indivíduos para organizações públicas específicas e essas não consigam responder a contento às suas preferências, isso virará uma fonte de desmotivação e evasão que serão crescentes com o tempo. Klein e Mascarenhas (2016), por sua vez, encontram que a remuneração é fator preponderante para a evasão. Assim, mesmo insatisfeito, o servidor bem remunerado não evadirá. Por outro lado, mesmo muito satisfeito, o servidor mal remunerado tenderá a evadir-se.

A probabilidade de ocorrência de matching entre empregados e organizações aumenta quando existe um alto nível de PSM. Esse melhor matching (e não a PSM) aumentará a satisfação no trabalho e diminuirá as expectativas de evasão no futuro (BRIGHT, 2008).

\footnotetext{
${ }^{2}$ Criada em 1932, pelo psicólogo norte-americano Rensis Likert, a Escala Likert é uma escala de resposta psicométrica amplamente usada para medir posturas e opiniões com um nível maior de nuance que uma simples pergunta de "sim" ou "não". Assim como toda métrica, a Escala Likert possui vantagens e desvantagens.
} 
Outro ponto de motivação é permitir que os trabalhadores desempenhem suas atividades em casa, quando possível. Isso é apontado como exemplo de motivação capaz de diminuir as taxas de evasão. No setor privado, esse resultado parece ocorrer (GADJENDRAN; HARRISON, 2007). Já no setor público, a diferença observada nas intenções de evasão entre os servidores que trabalhariam em casa e aqueles que não o fariam é estatisticamente significativa, mas muito baixa (10,3\% contra 10,7\%). Entretanto, a evasão é maior e estatisticamente significativa, entre aqueles que poderiam trabalhar em casa e são proibidos pelas suas respectivas chefias (CAILLIER, 2013).

Por fim, outro ponto relevante é o sistema de aposentadoria utilizado. Normalmente, acredita-se que o sistema público de benefícios definidos, ou seja, um sistema de distribuição em que o valor da aposentadoria é pré-definido, não se relacionando com o valor das contribuições feitas, tende a segurar mais os trabalhadores do que um sistema de contribuições definidas. Neste caso, um sistema de capitalização no qual o valor da aposentadoria é definido a partir das contribuições feitas na ativa pelo servidor. Isso foi observado para os servidores federais dos USA por Ippolito (2002) e para os servidores em primeiro ano de North Carolina (CLARK et al., 2015). Goldhaber, Grout e Holden (2015), analisando a mudança de plano ocorrida para os professores do Estado de Washington no final da década de 90, acham que as taxas de evasão de professores em seu primeiro ano são maiores no novo plano que no velho (mas o resultado é pouco robusto), (b) professores antigos que decidiram migrar para o novo plano apresentaram taxa de evasão menor que aqueles que ficaram no plano antigo (o que não é consistente com o esperado teoricamente ${ }^{3}$ ). O número de estudos empíricos relativos ao setor privado é bem mais extenso, mas seus resultados são bastante ambíguos.

\section{Diversidade nas organizações públicas}

A diversidade em relação ao gênero, à etnia ou à idade nas organizações americanas cresceu muito nas últimas décadas, principalmente devido às diversas leis de direitos civis e ações afirmativas. Essa tendência é maior nas organizações públicas que nas privadas.

\footnotetext{
${ }^{3}$ Como a migração foi voluntária, esse resultado pode ser explicado por meio de processo de auto-seleção. Ou seja, somente os professores que já planejavam deixar o setor público teriam feito a migração para o novo sistema.
} 
Do ponto de vista empírico, normalmente a diversidade é medida por intermédio de índice de concentração de Hilferding.

A diversidade nas organizações apresenta efeito ambíguo sobre a evasão. Por um lado, ela poderia diminuir a satisfação com o trabalho por, supostamente, aumentar os conflitos emocionais entre os empregados (elevando a taxa de evasão). Por outro, a diversidade poderia ampliar o caráter criativo e inovador das organizações, contribuindo para um melhor desempenho e maior adequação às mudanças e aos desafios no ambiente econômico. Dependendo do caráter da organização e do tipo de ambiente, mais ou menos dinâmico e inovador, em que essa está inserida, a diversidade apresentaria correlação positiva ou negativa com as taxas de evasão observadas.

Isso explica por que os resultados empíricos são contraditórios (ELY, 2004, JACKSON; JOSI, 2004; JACKSON; JOSI; ERHARDT, 2003). Diversos estudos empíricos mostram relação positiva entre diversidade e taxa de evasão (O’REILlY; CALDWELL; BARNETT, 1989). A taxa de evasão é maior entre as minorias existentes nas organizações porque não só apresentariam menor bem-estar como também seriam mais mal avaliadas por seus supervisores (Wagner; Pfeffer; O’Reilly, 1984; Sackett; Dubols, 1991; SACKett; Dubols; Noe, 1991; TSUI; EgAN; O’REILlY, 1992). Uma boa administração do trabalho em equipe neutralizaria os efeitos negativos da diversidade relativa a gênero (MoHAMMED; ANGELL, 2004). Isso ocorreria mais facilmente em relação à diversidade étnica com tarefas rotineiras e não com tarefas complexas (PELLED; EISENHARDT; XIN 1999).

Choi (2009) busca testar se uma gerência mais eficiente da diversidade é capaz de neutralizar os impactos dessa sobre a satisfação no trabalho e, portanto, sobre as taxas de evasão. Também busca estimar se os seus efeitos sobre as minorias são iguais aos efeitos sobre as maiorias. A gerência da diversidade é testada de duas formas: perguntandose diretamente aos empregados e mediante o número de queixas referentes ao Equal Employment Opportunity (EEO) existente em cada órgão. Os resultados encontrados mostram que a diversidade étnica ou etária é positivamente correlacionada com a taxa de evasão, mas não a de gênero. Uma boa gestão da diversidade, no caso da étnica, aumentaria a satisfação no trabalho e diminuiria as taxas de evasão. Não se encontraram resultados estatisticamente significativos sobre o tempo de permanência na organização ou sobre possíveis diferenças dos impactos da diversidade sobre homens ou mulheres. 
Também já foram testados os efeitos do gênero da chefia imediata sobre a satisfação e as taxas de evasão observadas. Existem duas alternativas: a importância do gênero caso o chefe imediato fosse homem ou mulher, ou a congruência entre os gêneros do empregado e da chefia imediata, no caso de terem o mesmo gênero. Utilizando dados de 34.000 professores de 6.500 localidades americanas distintas, relativas ao ano 20032004 , constatou-se que as mulheres são $76 \%$ dos professores, mas somente $46 \%$ dos supervisores. As satisfações de homens e mulheres com supervisores de mesmo sexo ou de mulheres com supervisores masculinos são iguais. Professores homens com supervisoras mulheres, porém, mostram menor satisfação (diferença estatisticamente significativa de 0,9 em escala de 4). O mesmo resultado, de forma inversa, ocorre com as taxas de evasão - homens e mulheres com supervisores do mesmo sexo ou mulheres com supervisores masculinos apresentam proporções de evasão iguais. Porém, homens supervisionados por mulheres exibem essa taxa maior (GRISSON; VIANO; SELIN, 2016).

\section{A carreira de EPPGG em Minas Gerais}

A carreira de Especialista em Políticas Públicas e Gestão Governamental (EPPGG) de Minas Gerais, originalmente denominada carreira de Administradores Públicos de Minas Gerais, foi formalmente criada em 9 de dezembro de 1986 pela Lei Estadual n ․ 9.360. A carreira é formada pelos concluintes do Curso Superior de Administração Pública (Csap), ministrado pela Fundação João Pinheiro (FJP) e autorizado pelo Decreto Federal no 92.745, de 04 de junho de 1986. O Csap teve como forma de ingresso, até 2015, um vestibular com caráter de concurso público. Para participar desse concurso público, a partir de 2016, o candidato deve, obrigatoriamente, ter efetuado inscrição no Exame Nacional do Ensino Médio (Enem), que passou a ser adotado como processo seletivo em fase única.

Ao longo de todo o curso, os alunos recebem uma bolsa de ajuda de custo que deve ser ressarcida ao Estado, caso o estudante desista da carreira antes do prazo pré-estabelecido. A Secretaria de Estado de Planejamento e Gestão de Minas Gerais (Seplag) se encarrega de alocar esses servidores entre os diversos órgãos e secretarias da administração estadual, buscando alavancar a qualidade da gestão pública em Minas Gerais. Ocorreu, numa primeira etapa do Csap, um único vestibular - os alunos concluintes 
foram empossados no Estado em 1992. O segundo vestibular para esse curso só ocorreu em 1993, continuando desde então. A carreira dos EPPGG em Minas Gerais figura junto e se relaciona com outras carreiras, em nível federal ou em outros estados da federação, na forma da Lei no15.304, de 11 de agosto de 2004 (CRUZ, 2005; OLIVEIRA, 2009; OLIVEIRA et al., 2012; AlmeidA; RodRIGUeS; SilveirA, 2019).

Em 2005, pesquisa empírica inédita sobre a evasão na carreira dos EPPGG em Minas Gerais já apontava um percentual de evasão em torno de $40 \%$. As perguntas básicas que nortearam aquela investigação, quais sejam, as condições em que a evasão ocorre, que fatores a determinam e em que direção segue os recursos humanos evadidos (CRUz, 2005), também foram as mesmas orientações para a investigação atual.

Apesar de todo o aparato, o governo mineiro parecia não fazer esforço para segurar seus EPPGG. Estudos posteriores revelaram que das 23 práticas e políticas de recursos humanos utilizadas pelo Estado em 2010 (antes da melhoria da carreira), somente cinco $(21,7 \%)$ contribuíam para a retenção dos EPPGG, enquanto seis $(26,1 \%)$ contribuíam para sua evasão (OLIVEIRA et al., 2012). Klein, Mascarenhas (2016), também em pesquisa realizada em 2010, encontram resultados similares. Esses analisam as carreiras de EPPGG em quatro estados brasileiros e no Governo Federal. Bahia e Governo Federal apresentaram remuneração e satisfação com o trabalho altas (e baixas taxas de evasão). Rio de Janeiro e São Paulo apresentaram ambos os fatores baixos (o que geraria uma evasão alta). Minas Gerais, por sua vez, apresentou baixa remuneração e alta satisfação. Essa última, porém, não era capaz de garantir a retenção dos EPPGG no Estado. Também com pesquisa realizada em 2010 com as carreiras de 11 diferentes estados (incluindo o Distrito Federal) e do Governo Federal, Andrade (2011) mostra que Minas Gerais apresentava o menor nível salarial de ingresso e a segunda menor média salarial (só ganhando do Acre) dessa carreira. Esse autor também identificou a existência de correlação entre nível salarial e taxa de evasão.

\subsection{A evasão na carreira de EPPGG no Estado de Minas Gerais}

O estudo da evasão na carreira de EPPGG é relevante porque, entre outras questões, a carreira tem o propósito de formar um corpo permanente e qualificado de especialistas para atuar no aperfeiçoamento institucional do aparelho do Estado. Ademais, a carreira 
tem natureza estratégica e, tanto no Governo Federal quanto em diversos estados brasileiros, os EPPGG são atores preparados para constituir uma burocracia estável e capacitada a fim de garantir a continuidade das políticas públicas após as mudanças de governo (FARIAS; GAetAnI, 2002; Cruz, 2005; Coelho; OlensCKI; Celso, 2011).

Em Minas Gerais, isso se evidencia pelo ingresso na carreira via concurso público, o que garante, de antemão, o pertencimento e o exercício em cargo público que a integra após a posse. Uma bolsa de estudo mensal, ofertada a cada estudante durante a formação, e a obrigatoriedade do ressarcimento ao Estado desse incentivo em caso de evasão ${ }^{4}$, confirmam a importância da carreira e os resultados que o Estado espera de seus integrantes.

A investigação sobre o tema baseou-se em pesquisa bibliográfica e levantamento de campo. Seu instrumento principal é o questionário, construído e inserido em formulário criado na plataforma Google forms, para coletar dados de natureza quantitativa e qualitativa sobre o processo da evasão, aqui entendido como desligamento definitivo da carreira em Minas Gerais.

O questionário foi estruturado em cinco blocos, quais sejam: informações básicas sobre o respondente; motivo(s) para o desligamento; referências acadêmicas; experiência profissional e situação após a evasão ${ }^{5}$. Acredita-se que esses sejam os aspectos indispensáveis à exploração do tema, de forma bem objetiva. Em sua parte final, foram solicitadas observações e sugestões para o respondente que se dispusesse a fazê-las.

O tempo para preenchimento do questionário foi estimado em cinco minutos e não houve obrigatoriedade de fornecer nenhum dado ou informação solicitada. A intenção foi conhecer os fatores que estimulam a permanência na carreira e os que concorrem para a decisão de se evadir. Buscou-se, ainda, obter informações sobre os momentos em que essa decisão é tomada e que aspectos da vida acadêmica e do exercício profissional na carreira colaboram para a sua ocorrência.

\footnotetext{
${ }^{4} \mathrm{~A}$ evasão nesse caso se refere ao desligamento definitivo da carreira. O estudo não abrangeu as evasões temporárias, como licenciamentos, disponibilidades para outros órgãos, para outras entidades das esferas públicas municipal, estadual ou federal.

${ }^{5}$ Em 2005, o primeiro estudo empírico sobre a evasão constatou que também aspectos relacionados à captação, formação e profissionalização dos futuros EPPGG, dentre eles: motivo(s) da escolha do curso; estágio obrigatório, lotação no serviço público, foram considerados igualmente influenciadores do processo de evasão.
} 
Para a identificação dos ex-EPPGG, foram feitos cruzamentos dos dados existentes nos cadastros da Escola de Governo da FJP com os dados fornecidos pelo Sindicato dos EPPGG. Foram muito importantes as informações complementares dos que hoje, permanecendo na carreira, tinham acesso aos colegas evadidos e nos ajudaram a localizálos, bem como de outros ex-EPPGG identificados, que além de preencher o questionário fizeram contatos com outros ex-EPPGG para também fazê-lo.

A remessa e a devolução do questionário foram feitas utilizando-se de e-mails e das redes sociais, como o Facebook, o WhatsApp, e o Linkedin. Foram obtidas 94 respostas no período compreendido entre junho e agosto de 2018 (em um universo de 589 evadidos).

\subsection{Os números dos entrantes no Csap}

Entre a primeira e a 29a turma do Csap, sendo que essa última ingressou no curso no primeiro semestre de 2012 e o concluiu no final de 2015 , ingressaram no curso 1.175 alunos, 519 mulheres e 656 homens, dos quais 624, brancos. Concluíram o curso e ingressaram na carreira, 942 alunos. Desses, 356 (abandonaram) desligaram-se da carreira e 586 nela permaneceram. 39\% de evasões ocorreram ainda durante o curso, na forma de desligamento definitivo da graduação. $61 \%$, após a conclusão do curso, na forma de desligamento definitivo da carreira. As mulheres apresentam a maior proporção de permanência na carreira (54\%). Respondem por 44\% dos ingressantes no CSAP e são $48 \%$ daqueles que não abandonaram a carreira. Menor proporção é observada nos homens (47\%). Os homens e os negros são os grupos com maior percentual de pessoas (pouco menos de 50\%) que abandonaram o estado (ou seja, não ficaram na carreira de EPPGG nem migraram para outra carreira). Apesar dos homens representarem $56 \%$ dos entrantes no Csap, correspondem a 64\% daqueles que migraram da carreira de EPPGG para outra do governo mineiro (Tabela 1). 
Tabela 1 | Ingressantes no Curso de Administração Pública (Csap) até 2016 por etnia e por gênero

\begin{tabular}{lcccc}
\hline & Permanece na & \multicolumn{2}{c}{ Saiu da carreira } & Total \\
\cline { 3 - 4 } Categoria & 307 & 23 & Saiu do Estado & \\
\hline Homem & 279 & 13 & 326 & 656 \\
Mulher & 323 & 21 & 227 & 519 \\
Branco & 263 & 15 & 280 & 624 \\
Negro & 586 & 36 & 273 & 551 \\
\hline Total & & 553 & 1175 \\
\hline
\end{tabular}

Fonte: Banco de dados da Pesquisa Percursos. Elaboração própria.

A proporção de homens nas turmas do Csap vem caindo continuamente desde a implantação do curso (Gráfico 1). Nas últimas turmas analisadas, a proporção de mulheres já era maior que a de homens. Já em relação à etnia, a proporção de alunos que se declararam pretos variou sistematicamente ao redor de 10\% (Gráfico 2).

\section{Gráfico 1 | Distribuição dos alunos ingressantes no Curso de Administração Pública (Csap) por turma e por gênero}

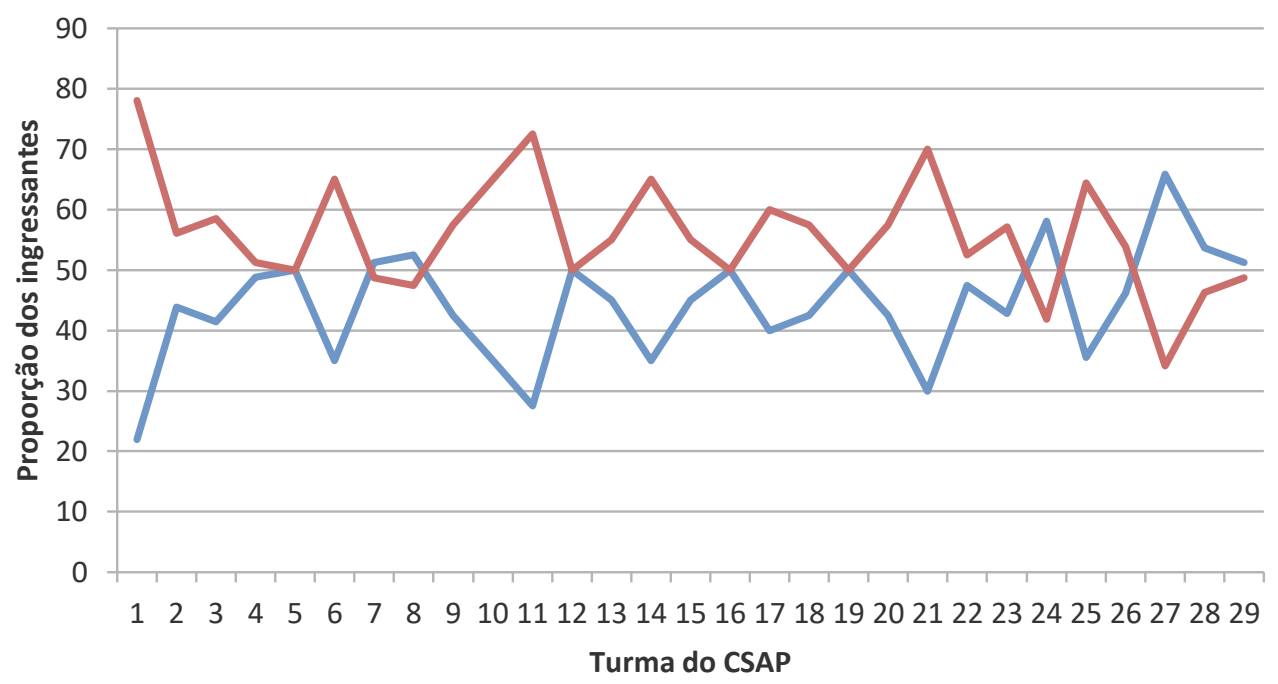

Mulher (\%) Homem (\%)

Fonte: Banco de dados da Pesquisa Percursos. Elaboração própria. 


\section{Gráfico 2 | Distribuição dos alunos ingressantes no Curso de Administração Pública} (Csap) por turma e por etnia

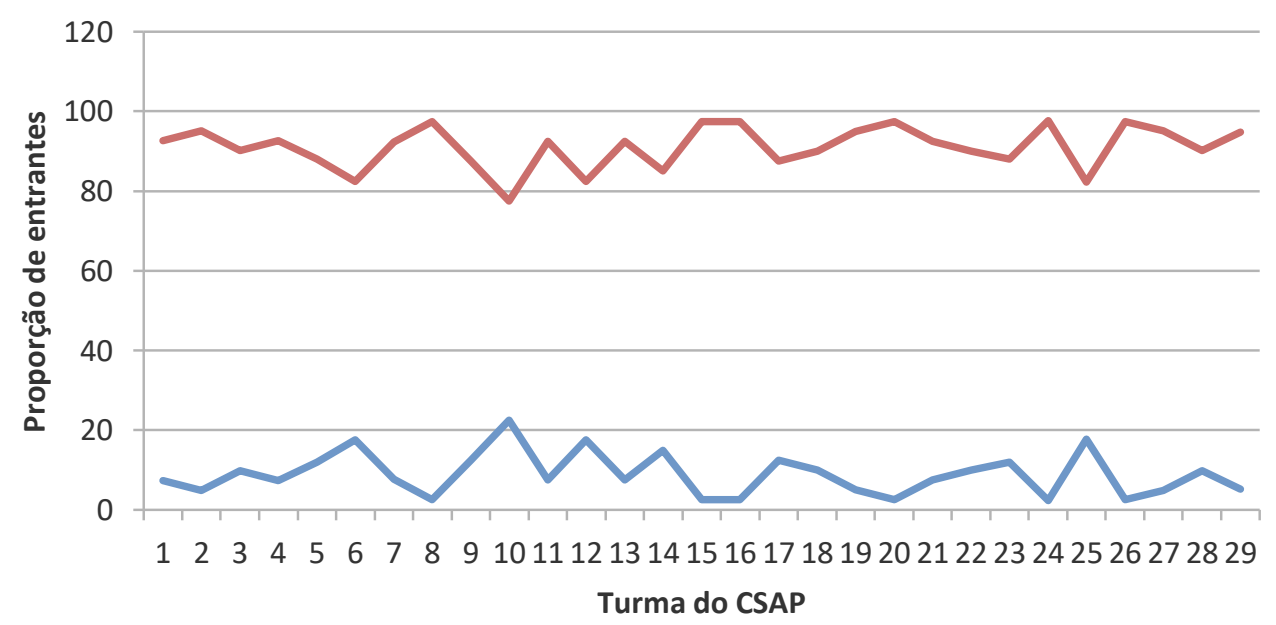

Preta (\%) Não Preta (\%)

Fonte: Banco de dados da Pesquisa Percursos. Elaboração própria.

Considerando somente os evadidos após a conclusão do curso, quanto mais distante no tempo o ano de formatura, maior o número de evadidos por turma (Gráfico 3). Isso não implica, porém, que as turmas mais antigas apresentem maior taxa de evasão. Esse resultado pode ser explicado pelo maior tempo de posse. Mesmo apresentando uma proporção constante de evadidos por ano, as turmas mais antigas apresentaram maior percentual de evadidos. A melhoria da carreira observada em 2012, porém, pode ter contribuído para a diminuição da taxa de evasão. 
Gráfico 3 | Percentual de evadidos da carreira de Especialista em Políticas Públicas e Gestão Governamental (EPPGG) de acordo com o ano de conclusão do Curso de Administração Pública (Csap)

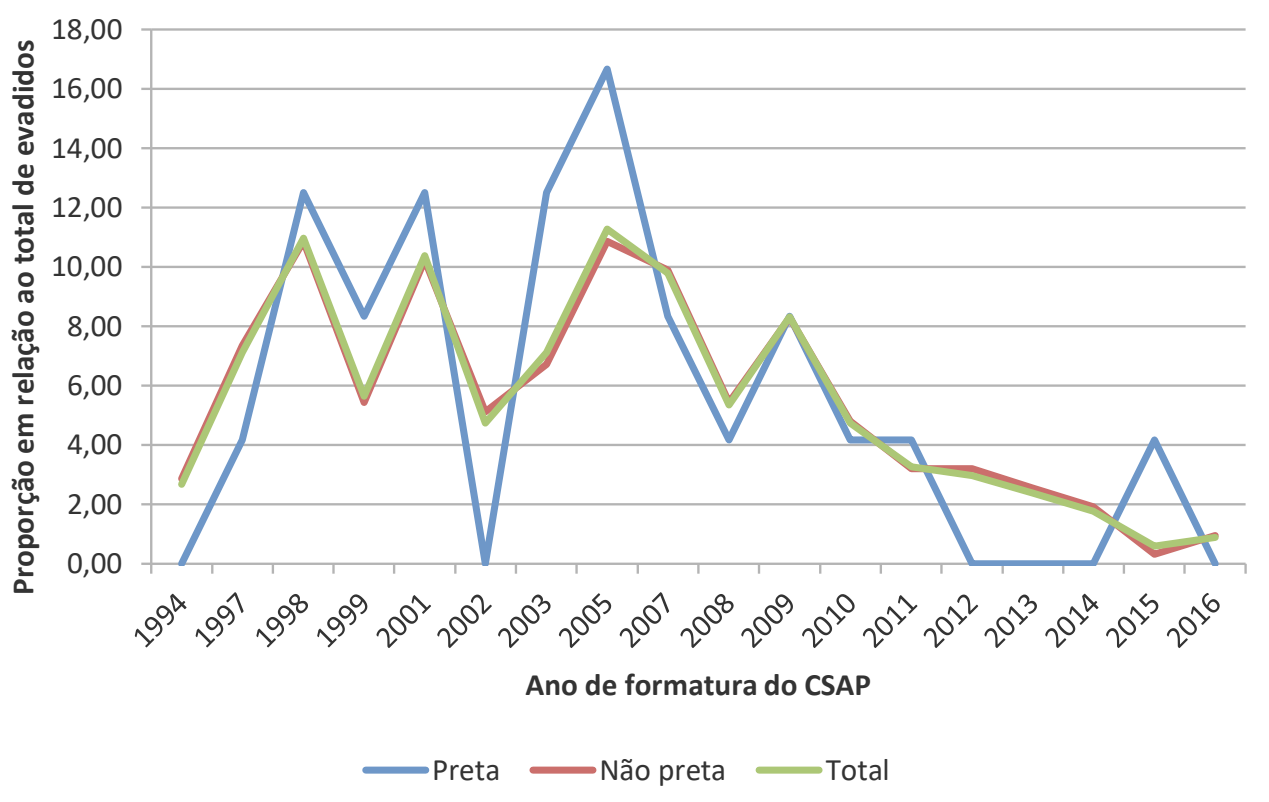

Fonte: Banco de dados da Pesquisa Percursos. Elaboração própria.

Não se observa qualquer padrão claro entre os evadidos quando esses são diferenciados seja em relação ao gênero, seja em relação à etnia (Gráficos 4 e 5). 
Gráfico 4 | Distribuição dos evadidos da carreira de Especialista em Políticas Públicas e Gestão Governamental (EPPGG) por gênero e por ano de conclusão do Curso de Administração Pública (Csap)

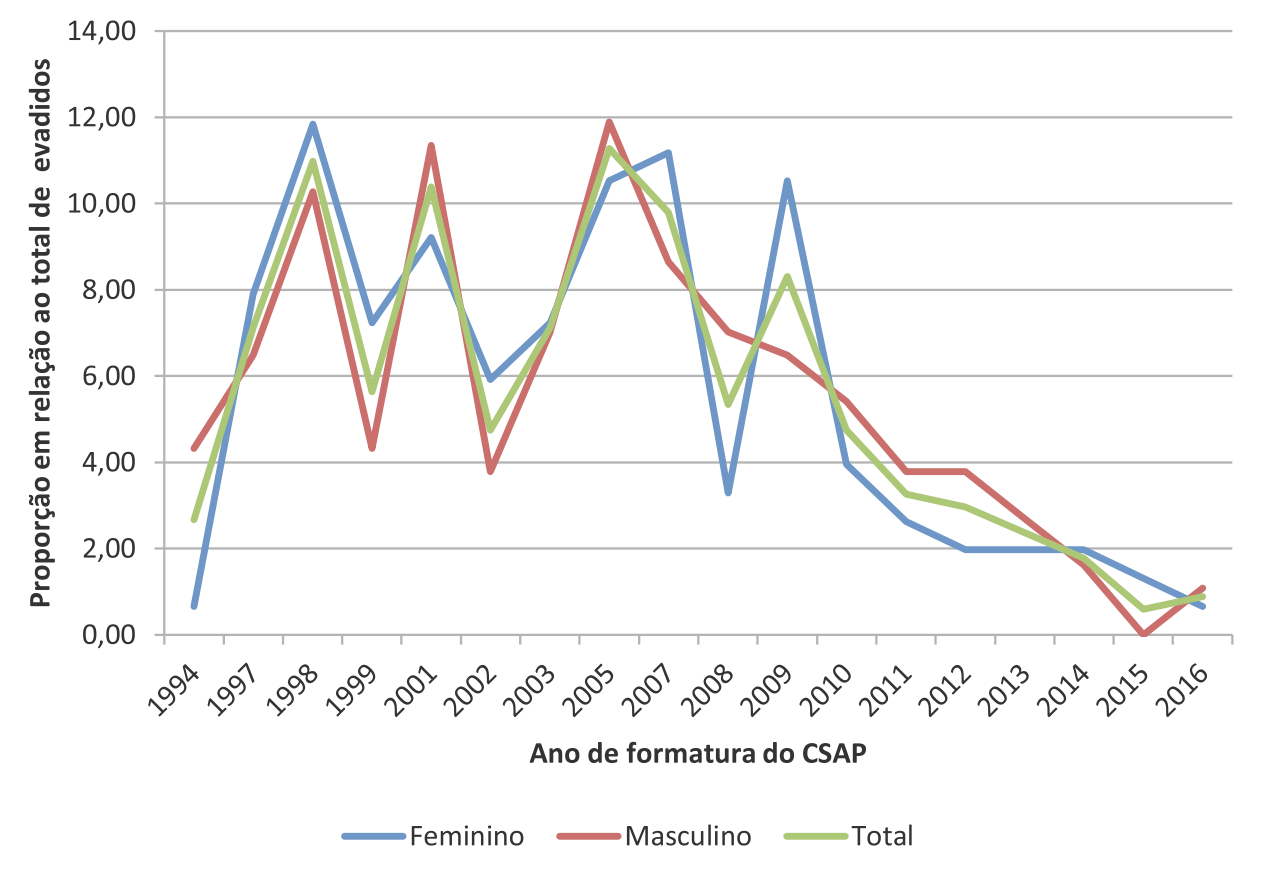

Fonte: Banco de dados da Pesquisa Percursos. Elaboração própria. 
Gráfico 5 | Distribuição dos evadidos da carreira de Especialista em Políticas Públicas e Gestão Governamental (EPPGG) por etnia e por ano de conclusão do Curso de Administração Pública (Csap)

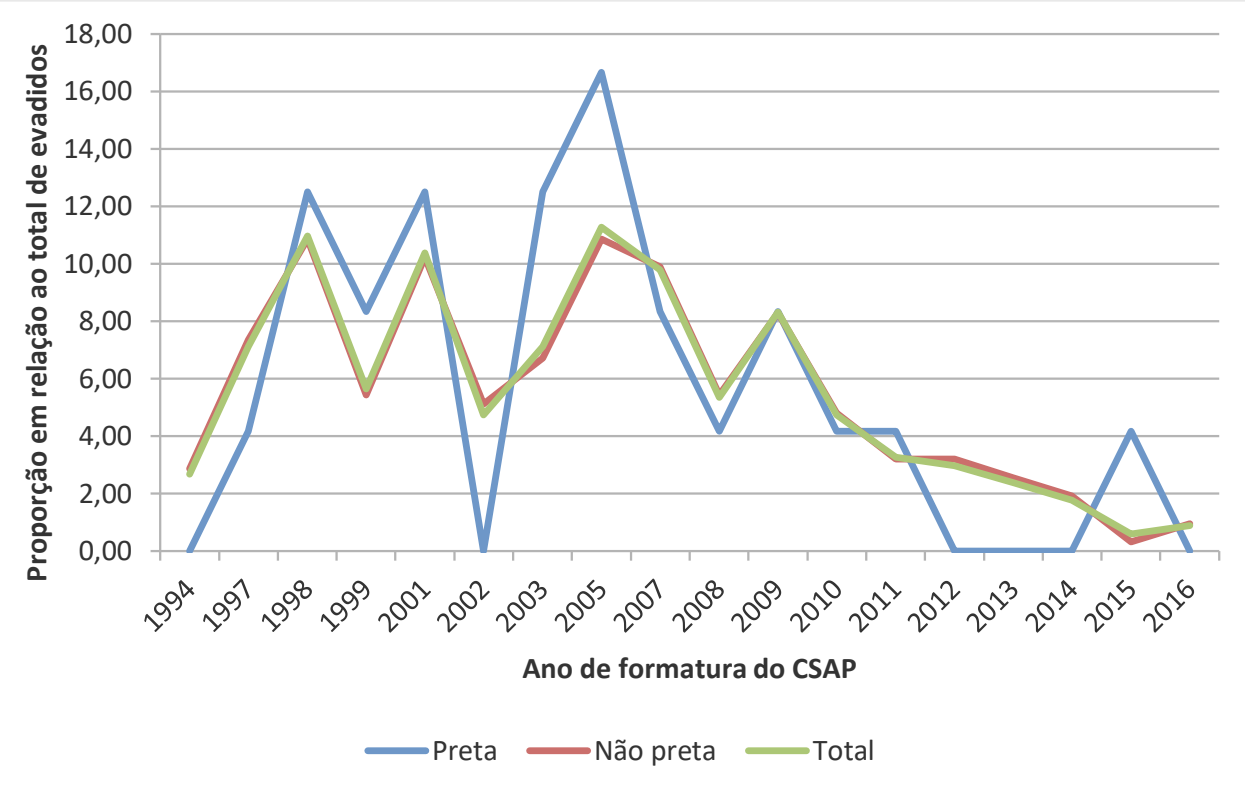

Fonte: Banco de dados da Pesquisa Percursos. Elaboração própria.

A assimetria interna de quem continua na carreira é bastante baixa, não sendo observadas diferenças relativas ao gênero ou à etnia. O salário médio, em 2016, de quem se manteve na carreira foi de pouco mais de oito mil reais. A sua idade média é de 31 anos. A idade média na posse foi de 25 anos (Tabela 2).

Tabela 2 | Ano médio de nascimento, salário médio, idade média em 2016 e na posse dos Especialistas em Políticas Públicas e Gestão Governamental (EPPGG) de Minas Gerais que permanecem na carreira por etnia e por gênero

\begin{tabular}{lccccc}
\hline & Masculino & Feminino & Branco & Negro & Total \\
\hline Ano médio de nascimento & $1,984.43$ & $1,985.99$ & $1,985.38$ & $1,984.97$ & $1,985.17$ \\
Salário médio & $8,306.75$ & $8,306.47$ & $8,299.84$ & $8,324.25$ & $8,306.62$ \\
\hline Idade média em 2016 & 31.57 & 30.01 & 30.62 & 31.03 & 30.83 \\
Idade média na posse & 25.12 & 24.06 & 24.37 & 24.86 & 24.61 \\
\hline
\end{tabular}

Fonte: Banco de dados da Pesquisa Percursos. Elaboração própria. 
O salário dos EPPGG cresce linearmente com os anos de experiência na carreira. O salário inicial médio é de quatro mil reais. Com 16 anos de experiência, observa-se o maior salário médio - pouco menos de 17 mil reais. A média salarial dos servidores com maior experiência se situa entre 12 e 15 mil reais (Gráfico 6).

Gráfico 6 | Salários médios mínimos e máximos dos Especialistas em Políticas Públicas e Gestão Governamental (EPPGG) em Minas Gerais por anos de experiência na carreira $-2016$

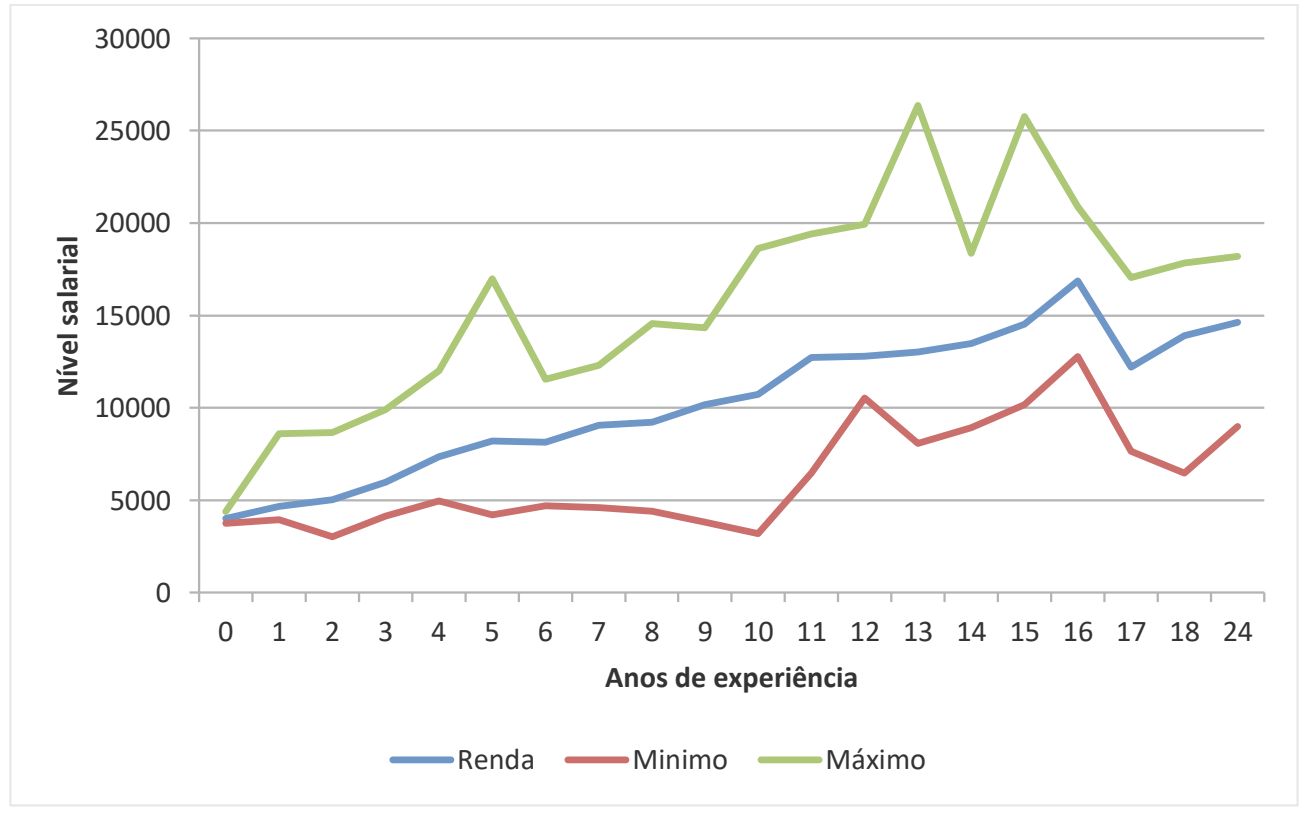

Fonte: Banco de dados da Pesquisa Percursos. Elaboração própria.

A distribuição dos servidores por faixas salariais é muito similar entre qualquer um dos grupos analisados, homens, mulheres, brancos, negros e total. Para todos esses, praticamente a metade recebe entre $\mathrm{R} \$ 4.000$ e $\mathrm{R} \$ 7.500$ (Gráfico 7). Outros resultados de nossa pesquisa (FJP, 2019) ajudam a entender melhor esse quadro no caso das diferenças de gênero. Mulheres seriam mais eficientes para subir na carreira (fruto da regulação institucionalizada e impessoal dessa). Já os homens ocupariam uma maior proporção de cargos comissionados. Ou seja, apesar da igualdade observada entre os gêneros em relação à remuneração, diferenças entre esses ainda persistiriam. 
Gráfico 7 | Distribuição dos Especialistas em Políticas Públicas e Gestão Governamental (EPPGG) em Minas Gerais de acordo com sua faixa salarial por gênero e por etnia 2016

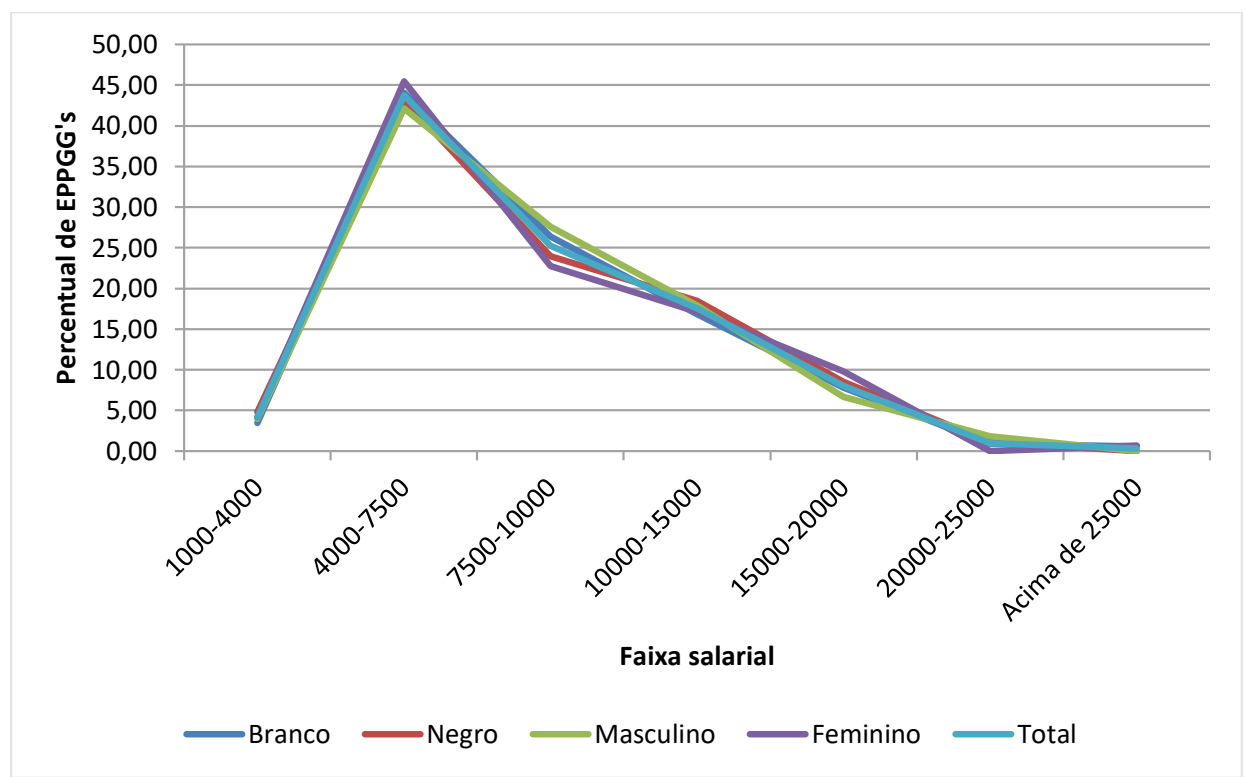

Fonte: Banco de dados da Pesquisa Percursos. Elaboração própria.

\section{Os evadidos da carreira}

Obtiveram-se 94 respostas ao questionário aplicado junto aos evadidos da carreira de EPPGG. Isso representa quase $20 \%$ do total de evadidos. Nesses, 58 foram homens (62\% do total), 35 mulheres (37\%) e 01 preferiu não se declarar. Essa distribuição é relativamente similar àquela dos entrantes do Csap (44\% de mulheres e 56\% de homens) ou dos evadidos ( $41 \%$ de mulheres e $59 \%$ de homens). Já a distribuição por etnia não reproduziu tão bem essas distribuições. Somente um respondente se declarou preto (somente $1 \%$ do total) - 9\% dos entrantes e $8 \%$ dos evadidos seriam pretos. Em nossa amostra, 62 se declararam brancos (66\% do total), 24 pardos (26\%), três amarelos (3\%), um indígena (1\%) e três não se declararam (Tabela 3). Cumpre notar que essa amostra não é aleatória. Assim, os resultados obtidos devem ser olhados com cautela (e isso não mudaria mesmo que nossa amostra apresentasse as mesmas distribuições por raça e gênero dos evadidos). 
Tabela 3 | Egressos respondentes do questionário aplicado por etnia e por sexo

\begin{tabular}{lcccc} 
& Homem & Mulher & Não informou & Total Geral \\
\hline Amarela & 2 & 1 & 0 & 3 \\
Branca & 35 & 27 & 0 & 62 \\
Indígena & 1 & 0 & 0 & 1 \\
Parda & 18 & 5 & 1 & 24 \\
Preta & 0 & 1 & 0 & 1 \\
Não informou & 2 & 1 & 0 & 3 \\
\hline Total Geral & 58 & 35 & 1 & 94 \\
\hline
\end{tabular}

Fonte: Banco de dados da Pesquisa Percursos. Elaboração própria.

Praticamente todas as turmas do Csap contaram com ao menos um respondente do questionário. As exceções são os Csap I e XXVIII. O Csap com o maior número de respondentes é o XII (cuja posse no cargo se deu no início de 2007), com 13 participantes (14\% do total), seguido do XI (posse no início de 2006), com sete respostas ou 7,5\% do total (Tabela 4). A distribuição por ano de formatura apresenta a mesma característica. Somente o ano de 2003 não conta com representantes em nossa amostra. O ano mais representado é o de 2006 (14 respondentes ou 15\% do total), seguido do de $2009-12$ respondentes ou $13 \%$ do total (Tabela 5 ). 
Tabela 4 | Egressos respondentes do questionário aplicado por turma do Curso de Administração Pública (Csap)

\begin{tabular}{|c|c|c|}
\hline \multirow{2}{*}{ Turma do Csap } & \multicolumn{2}{|c|}{ Egressos respondentes } \\
\hline & Valor absoluto & Valor percentual \\
\hline II & 1 & 1,06 \\
\hline III & 2 & 2,13 \\
\hline IV & 3 & 3,19 \\
\hline V & 3 & 3,19 \\
\hline VI & 5 & 5,32 \\
\hline VII & 2 & 2,13 \\
\hline VIII & 3 & 3,19 \\
\hline IX & 2 & 2,13 \\
\hline$x$ & 3 & 3,19 \\
\hline$X I$ & 7 & 7,45 \\
\hline XII & 13 & 13,83 \\
\hline XIII & 6 & 6,38 \\
\hline XIV & 4 & 4,26 \\
\hline$x V$ & 6 & 6,38 \\
\hline $\mathrm{XVI}$ & 5 & 5,32 \\
\hline XVII & 6 & 6,38 \\
\hline$X V I I I$ & 1 & 1,06 \\
\hline XIX & 1 & 1,06 \\
\hline$x x$ & 2 & 2,13 \\
\hline$X X I$ & 6 & 6,38 \\
\hline XXII & 2 & 2,13 \\
\hline XXIII & 2 & 2,13 \\
\hline XXIV & 2 & 2,13 \\
\hline$x x V$ & 1 & 1,06 \\
\hline $\mathrm{XXVI}$ & 1 & 1,06 \\
\hline XXVII & 1 & 1,06 \\
\hline XXIX & 2 & 2,13 \\
\hline Não informou & 2 & 2,13 \\
\hline Total Geral & 94 & 100,00 \\
\hline
\end{tabular}

Fonte: Banco de dados da Pesquisa Percursos. Elaboração própria. 
Tabela 5 | Egressos respondentes do questionário aplicado por ano de formatura do Curso de Administração Pública (Csap)

\begin{tabular}{|c|c|c|}
\hline \multirow{2}{*}{ Ano de formatura } & \multicolumn{2}{|c|}{ Egressos respondentes } \\
\hline & Valor absoluto & Valor percentual \\
\hline 1997 & 1 & 1,06 \\
\hline 1998 & 5 & 5,32 \\
\hline 1999 & 3 & 3,19 \\
\hline 2000 & 4 & 4,26 \\
\hline 2001 & 5 & 5,32 \\
\hline 2002 & 1 & 1,06 \\
\hline 2004 & 3 & 3,19 \\
\hline 2005 & 6 & 6,38 \\
\hline 2006 & 14 & 14,89 \\
\hline 2007 & 5 & 5,32 \\
\hline 2008 & 9 & 9,57 \\
\hline 2009 & 12 & 12,77 \\
\hline 2010 & 3 & 3,19 \\
\hline 2011 & 6 & 6,38 \\
\hline 2012 & 6 & 6,38 \\
\hline 2013 & 3 & 3,19 \\
\hline 2014 & 2 & 2,13 \\
\hline 2015 & 2 & 2,13 \\
\hline Não informou & 4 & 4,26 \\
\hline Total geral & 94 & 100,00 \\
\hline
\end{tabular}

Fonte: Banco de dados da Pesquisa Percursos. Elaboração própria.

O ano de 2010 representa o pico de evasões na amostra analisada (16, sendo 12 homens e quatro mulheres). Em segundo lugar, está 2012 (13 evasões, sendo cinco homens e oito mulheres). A melhoria da carreira provavelmente explica a queda da evasão após essas datas. O valor máximo observado para os homens ocorreu antes do observado para as mulheres (em percentual, ambos os valores seriam iguais, ou seja, praticamente um quarto dos homens da amostra evadiu em 2010, enquanto um quarto das mulheres o fez em 2012). Sistematicamente o número de evadidos cai a partir de 2012 (Gráfico 8). 
A análise por etnia é distinta. Brancos apresentaram dois picos claros, em 2010 e 2012. Negros se mantiveram relativamente constantes no período analisado (Gráfico 9).

Gráfico 8 | Saídas definitivas da carreira de Especialista em Políticas Públicas e Gestão Governamental (EPPGG) por ano e por sexo

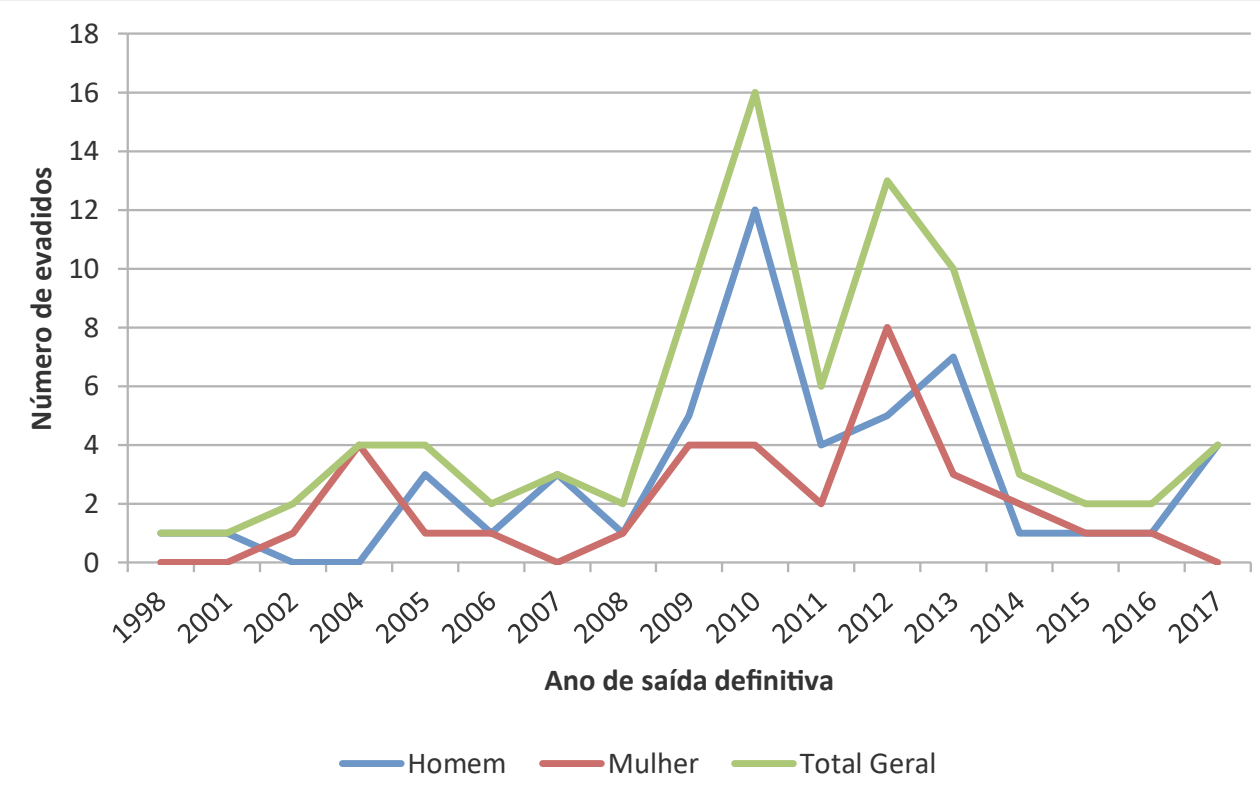

Fonte: Banco de dados da Pesquisa Percursos. Elaboração própria. 
Gráfico 9 | Saídas definitivas da carreira de Especialista em Políticas Públicas e Gestão Governamental (EPPGG) por ano e por etnia

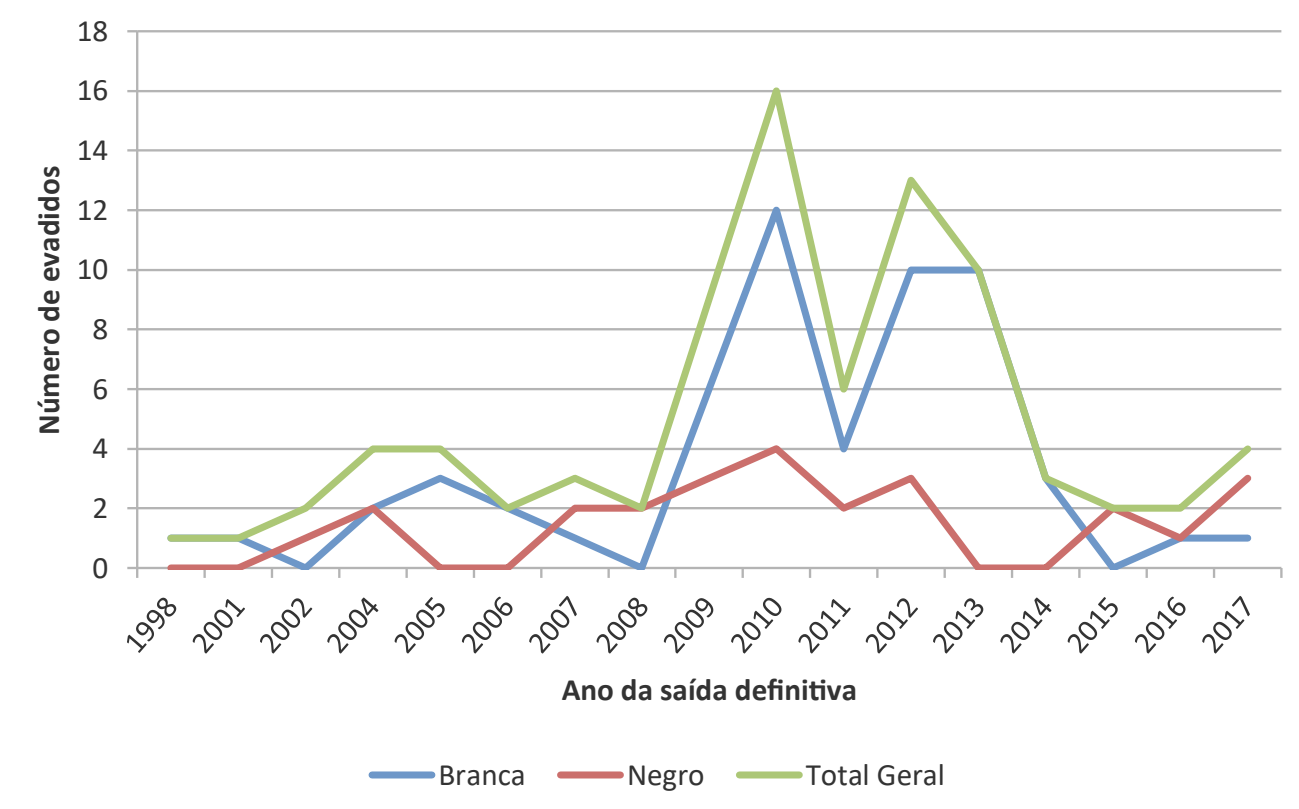

Fonte: Banco de dados da Pesquisa Percursos. Elaboração própria.

Mais da metade da amostra analisada evadiu-se após o cumprimento do estágio probatório, indicando uma preocupação com a possibilidade de o evadido ter que ressarcir o Estado por sua saída da carreira. Um pouco mais de um quarto evadiu durante esse período. Somente uma pequena parte evadiu antes de sua posse (Tabela 6).

Tabela 6 | Número de evadidos da carreira de Especialista em Políticas Públicas e Gestão Governamental (EPPGG) de acordo com o momento da saída definitiva da carreira

\begin{tabular}{lrr}
\hline Momento de saída da carreira & Número & Percentual \\
\hline Antes da posse & 7 & 7.45 \\
Exoneração durante o cumprimento do estágio probatório & 26 & 27.66 \\
Exoneração após cumprimento do estágio probatório & 52 & 55.32 \\
Na aposentadoria & 1 & 1.06 \\
Não informado & 8 & 8.51 \\
\hline
\end{tabular}

Fonte: Banco de dados da Pesquisa Percursos. Elaboração própria.

A evasão ocorre principalmente com pessoas mais jovens e nos primeiros anos de 
sua carreira. E isso ocorre tanto com os homens quanto com as mulheres. A maioria das evasões ocorre quando o servidor tem entre 24 e 29 anos (Gráfico 10), momento em que sua experiência na carreira se situa entre dois e quatro anos (Gráfico 11).

Gráfico 10 | Proporção de evadidos da carreira de Especialista em Políticas Públicas e Gestão Governamental (EPPGG) de acordo com sua idade no ano de evasão

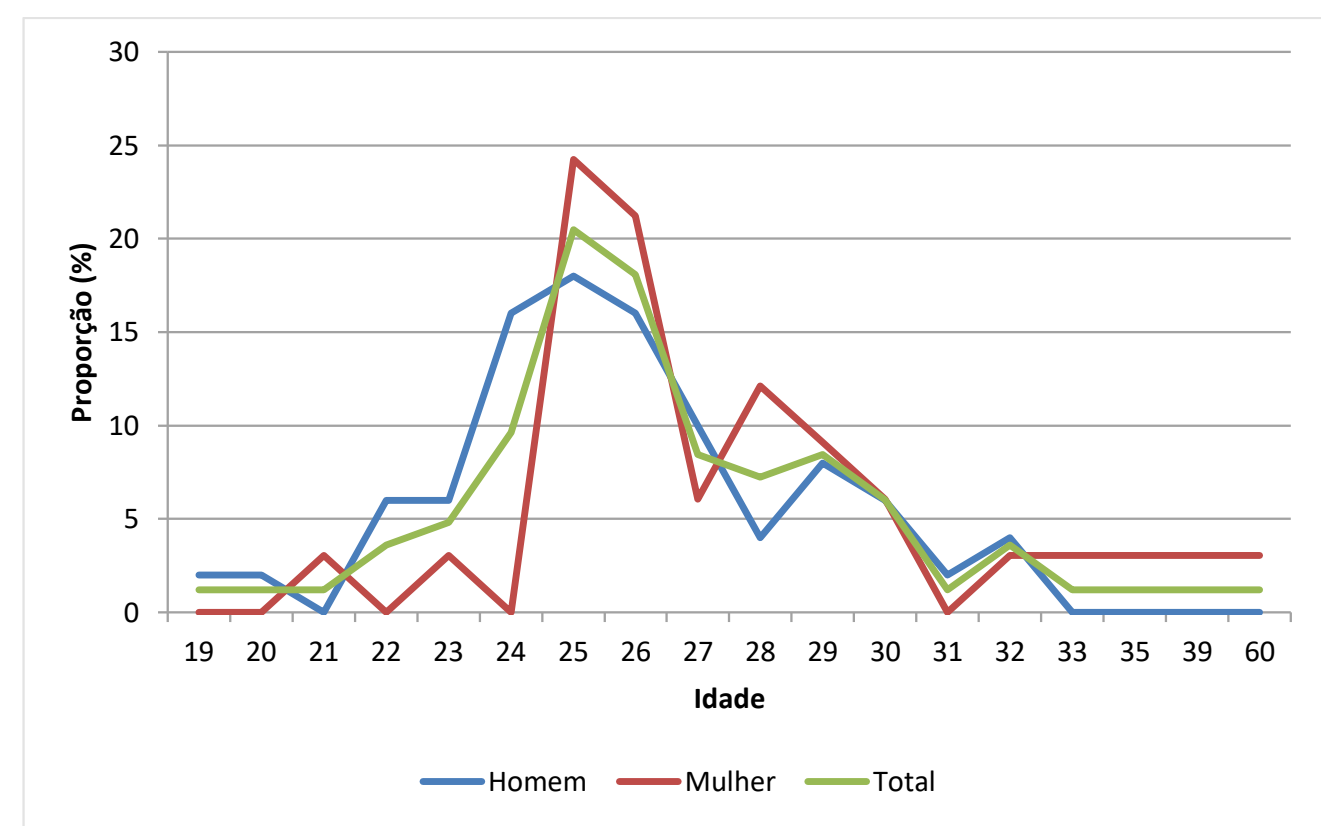

Fonte: Banco de dados da Pesquisa Percursos. Elaboração própria. 
Gráfico 11 | Proporção de evadidos da carreira de Especialista em Políticas Públicas e Gestão Governamental (EPPGG) de acordo com o período de tempo que ficou no Estado

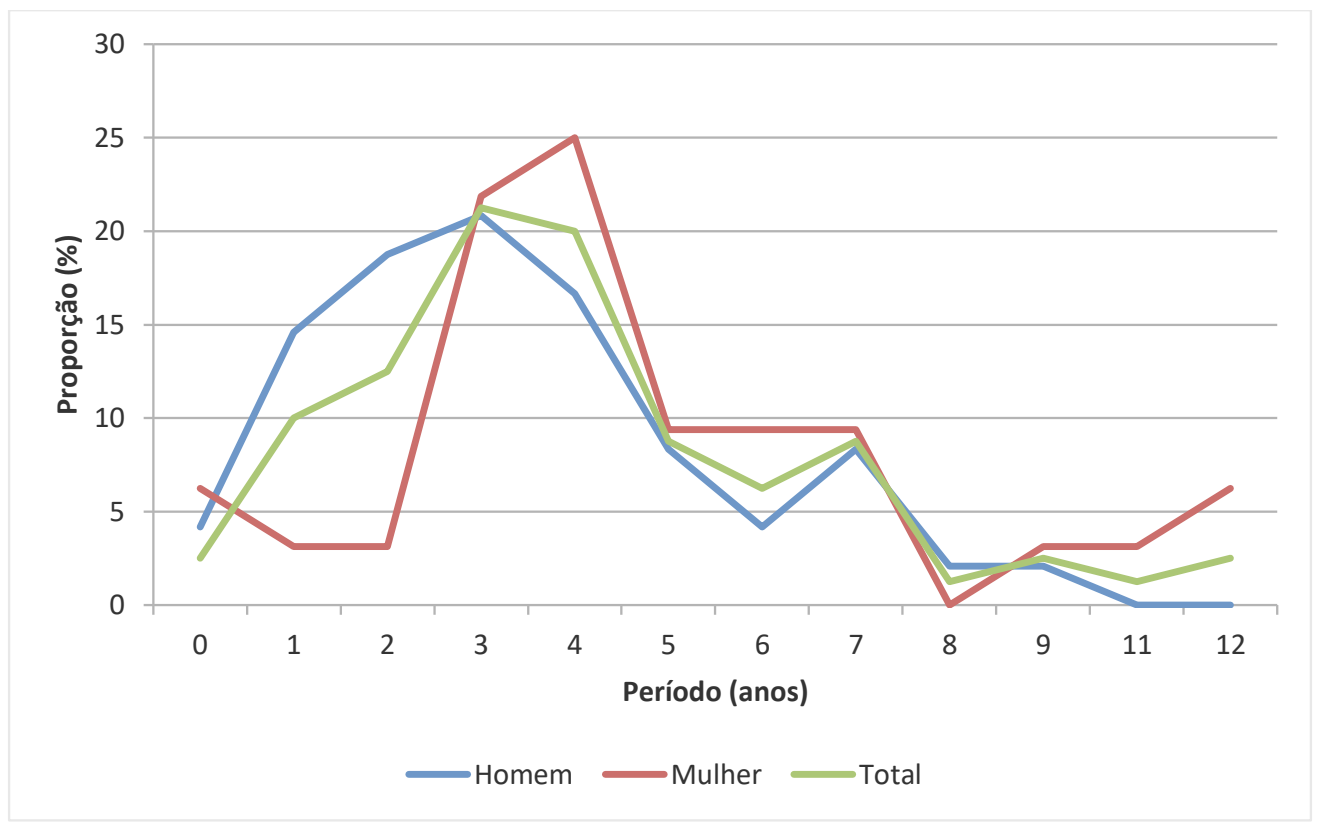

Fonte: Banco de dados da Pesquisa Percursos. Elaboração própria.

Os evadidos não utilizaram licenças temporárias antes da evasão para consolidar suas decisões. Somente uma pequena proporção da amostra (14\%) se afastou temporariamente antes de sua evasão final (Gráfico 12). O arrependimento entre os evadidos também é baixo. Somente $16 \%$ dos evadidos ouvidos (14 servidores: sete homens e sete mulheres) se declararam arrependidos de terem saído da carreira (Gráfico 13). O setor público federal absorveu quase metade dos evadidos pesquisados (47\%). O setor público estadual vem em segundo lugar (28\%). O setor privado absorveu um décimo desses profissionais (Gráfico 14). A migração para o Governo Federal (com carreira mais bem remunerada) de metade dos evadidos indica a importância da remuneração para a retenção dos talentos, uma vez que as carreiras são similares (o desapontamento com o setor público faria o evadido buscar uma recolocação fora dele). 
Gráfico 12 | Proporção de Especialista em Políticas Públicas e Gestão Governamental (EPPGG) evadidos que se licenciaram temporariamente antes da evasão

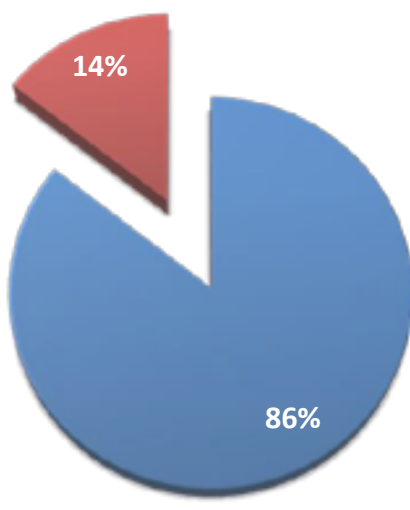

Fonte: Banco de dados da Pesquisa Percursos. Elaboração própria.

Gráfico 13 | Proporção de Especialista em Políticas Públicas e Gestão Governamental (EPPGG) evadidos que se arrependeram devido à evasão

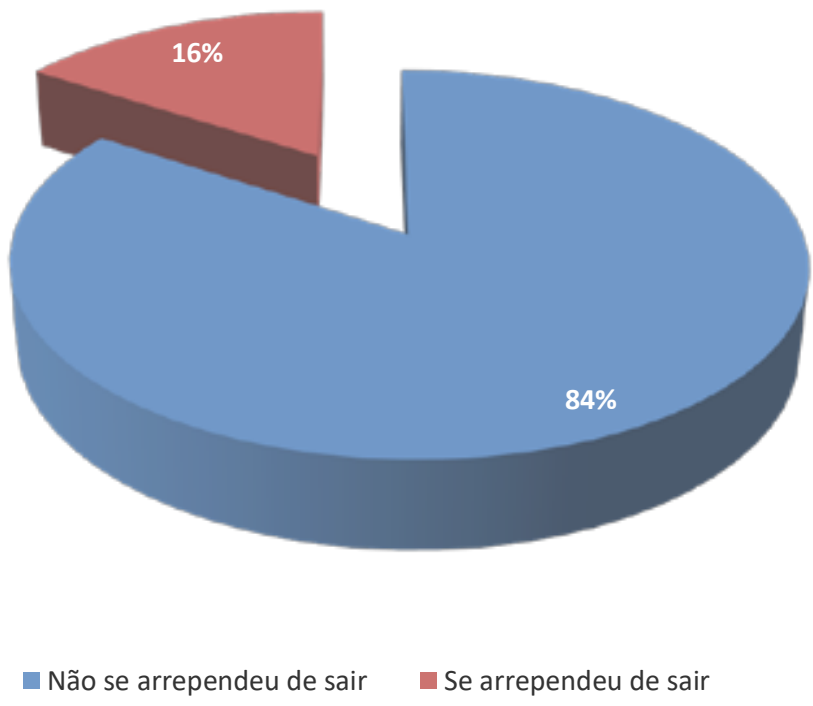

Fonte: Banco de dados da Pesquisa Percursos. Elaboração própria. 


\section{Gráfico 14 | Proporção de Especialistas em Políticas Públicas e Gestão Governamental} (EPPGG) evadidos de acordo com o atual setor de atuação

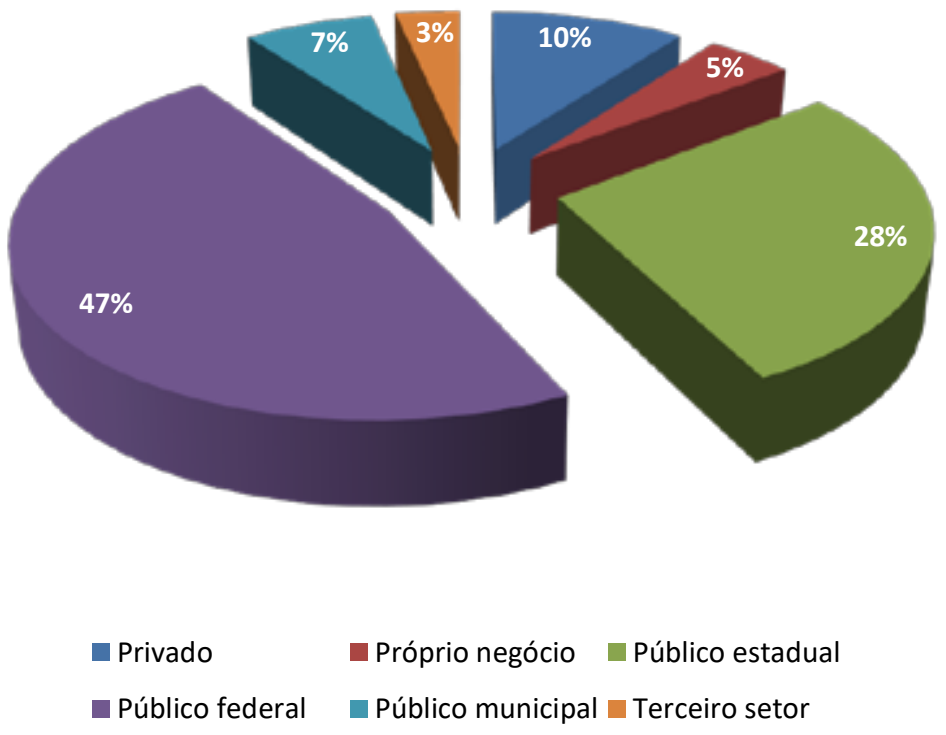

Fonte: Banco de dados da Pesquisa Percursos. Elaboração própria.

O salário médio dos evadidos da carreira é de pouco mais de 16 mil reais. Devido ao pequeno tamanho da amostra (e ainda menor quantidade de representantes de minorias), deve-se olhar com cautela a distribuição dos rendimentos médios. O salário médio recebido pelos homens evadidos é de $\mathrm{R} \$ 16.798,25$. Já as mulheres recebem (em média) $\mathrm{R} \$ 15.036,76$. Os brancos recebem $\mathrm{R} \$ 15.540,98$ enquanto os negros (não brancos) $\mathrm{R} \$ 17.741,38$ - um único respondente que se declarou preto está com salário de $\mathrm{R} \$ 20$ mil (Tabela 7). Ou seja, parece claro que os evadidos apresentam rendimentos maiores que aqueles observados para a carreira. 
Tabela 7 | Salários médios dos evadidos da carreira de Especialista em Políticas Públicas e Gestão Governamental (EPPGG) por etnia e por gênero

\begin{tabular}{l|r}
\hline Categoria & \multicolumn{1}{c}{ Salário Médio } \\
\hline Homem & $16.798,25$ \\
Mulher & $15.036,76$ \\
Amarela & $12.916,67$ \\
Branca & $15.540,98$ \\
Indígena & $26.000,00$ \\
Parda & $17.906,25$ \\
Preta & $20.000,00$ \\
Negro & $17.741,38$ \\
\hline \multicolumn{2}{l}{ Total Geral } \\
\hline
\end{tabular}

Fonte: Banco de dados da Pesquisa Percursos. Elaboração própria.

A proporção de mulheres recebendo entre cinco e 15 mil reais é maior que aquela observada para os homens. Apesar de não existirem mulheres com salário menor que cinco mil (quase 9\% dos homens estão nessa faixa), 43\% dos homens recebem entre 15 e 25 mil, (somente 23,5\% das mulheres estão nessa faixa), o que parece indicar a existência de teto de vidro relativo a elas nas carreiras pós-evasão do setor público (Gráfico 15).

\section{Gráfico 15 | Distribuição dos rendimentos dos evadidos da carreira de Especialista em Políticas Públicas e Gestão Governamental (EPPGG) por gênero}

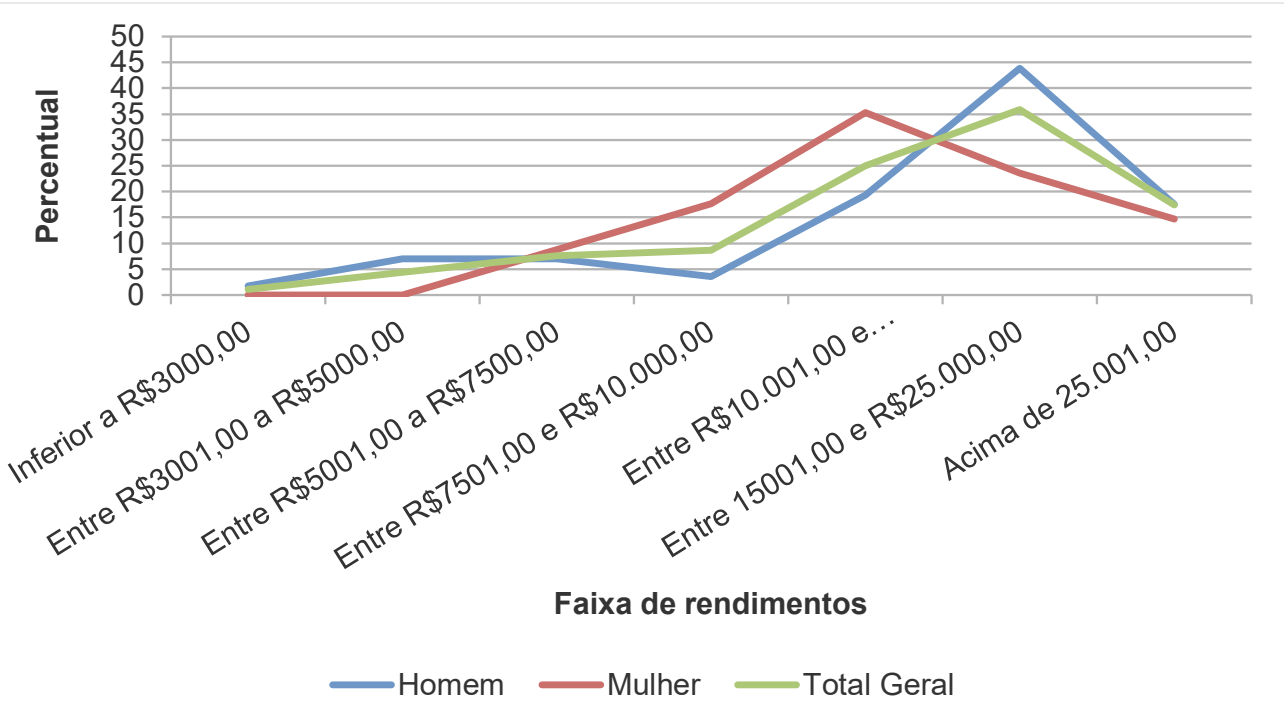

Fonte: Banco de dados da Pesquisa Percursos. Elaboração própria. 
O quadro é distinto em relação aos negros. Esses apresentam proporções maiores que os brancos em duas faixas distintas, aquela entre cinco mil e $R \$ 7.500$ e acima de 25 mil (o que indica a não existência de teto de vidro no mercado de trabalho referente à etnia). Porém, isso deve ser analisado com cautela devido ao tamanho da amostra. Enquanto sete em 61 brancos estão na maior faixa de renda, o mesmo ocorre com oito de 29 negros (Gráfico 16).

\section{Gráfico 16 | Distribuição dos rendimentos dos evadidos da carreira de Especialista em Políticas Públicas e Gestão Governamental (EPPGG) por etnia}

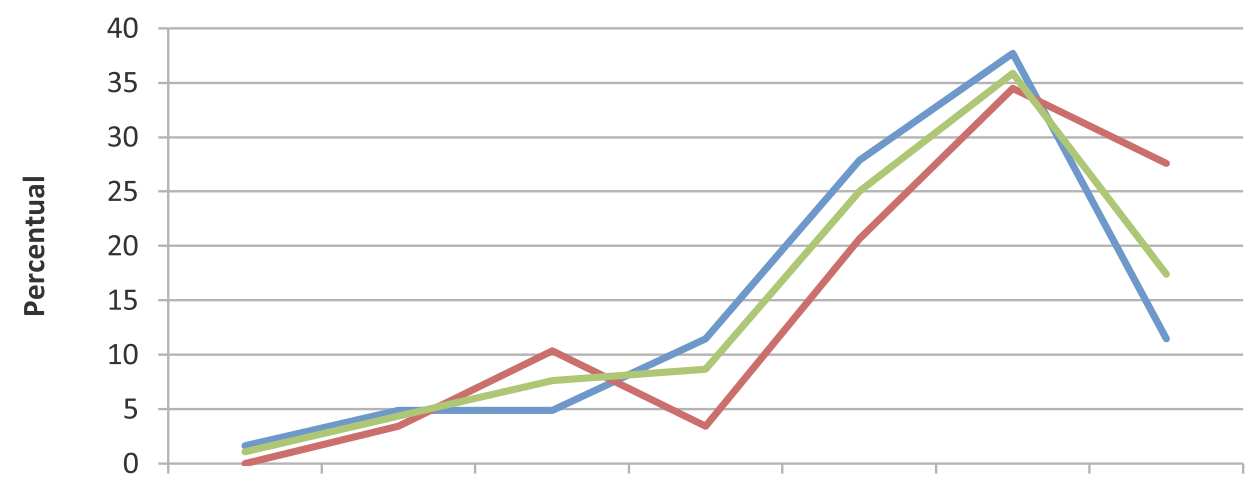

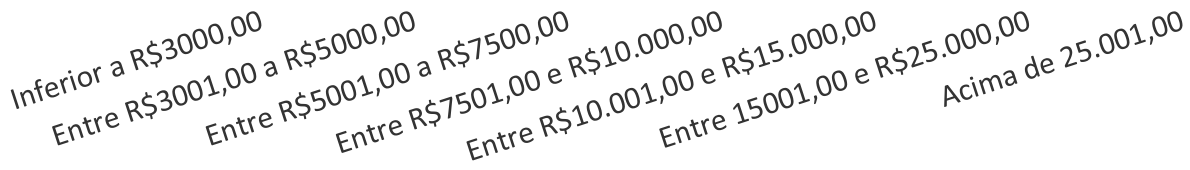

Faixa de rendimentos

Branca Negro Total Geral

Fonte: Banco de dados da Pesquisa Percursos. Elaboração própria.

O salário médio daqueles que se arrependeram de sair da carreira era menor que aquele dos que não se arrependeram. Enquanto quase metade do primeiro grupo (43\%) ganhava até $\mathrm{R} \$ 10$ mil, isto ocorreu com menos de um quinto do segundo grupo ou $17 \%$ (Gráfico 17). 
Gráfico 17 | Distribuição dos evadidos da carreira de Especialista em Políticas Públicas e Gestão Governamental (EPPGG) arrependidos de a terem abandonado e evadidos que não se arrependeram de acordo com suas faixas salariais

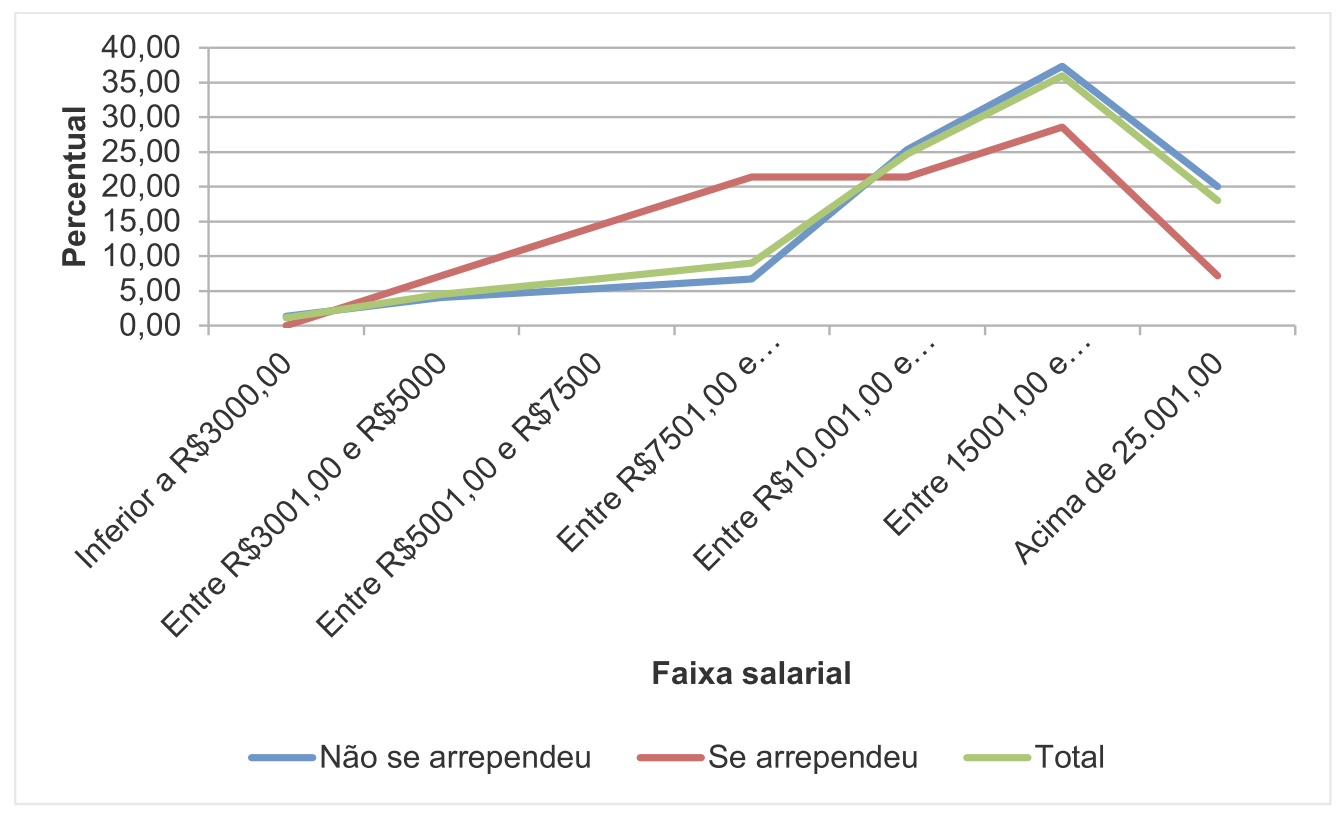

Fonte: Banco de dados da Pesquisa Percursos. Elaboração própria.

Desses que se arrependeram, oito (quatro homens e quatro mulheres) disseram que isso se deu devido à "reestruturação da carreira após a saída". Cinco (quatro homens e uma mulher) disseram querer ser "EPPGG em Minas Gerais". Somente três (dois homens e uma mulher) concordaram com ambas as razões.

Todos os sete que se evadiram antes da posse declararam que houve "aprovação em outro concurso público". Curioso é que três (dois homens e uma mulher) declararam também que a "carreira pública não era o que almejava".

78 evadidos o fizeram durante ou depois do estágio probatório (46 homens, 31 mulheres e um que não respondeu qual é o seu sexo). Dois motivos se destacam para essa evasão: 58 (33 homens, 24 mulheres e um de sexo desconhecido) apontam como motivo terem sido aprovados em outro concurso público; já 51 (30 homens e 21 mulheres) disseram querer uma remuneração maior. Desses grupos, 43 evadidos apontaram ambos os motivos para sua desistência. Existem dois picos relacionados a esses grupos, em 2010 
e 2012. Após esse último ano, as evasões relacionadas a essas causas diminuem muito (Gráfico 18). Dez evadidos declararam insatisfação com o setor público. Porém, metade deles (cinco) declarou ter passado em outro concurso público. Ou seja, parece claro que o principal motivo relativo ao abandono da carreira é o baixo pagamento. A sua melhoria levou a uma queda das desistências. A maioria dos evadidos (tanto total quanto aqueles que declararam ter se evadido devido a outro concurso público ou à busca de remuneração maior) continua a trabalhar no setor público, principalmente no federal, mas também no estadual (Gráfico 19).

\section{Gráfico 18 | Evadidos da carreira de Especialista em Políticas Públicas e Gestão Governamental (EPPGG) por motivação da evasão}

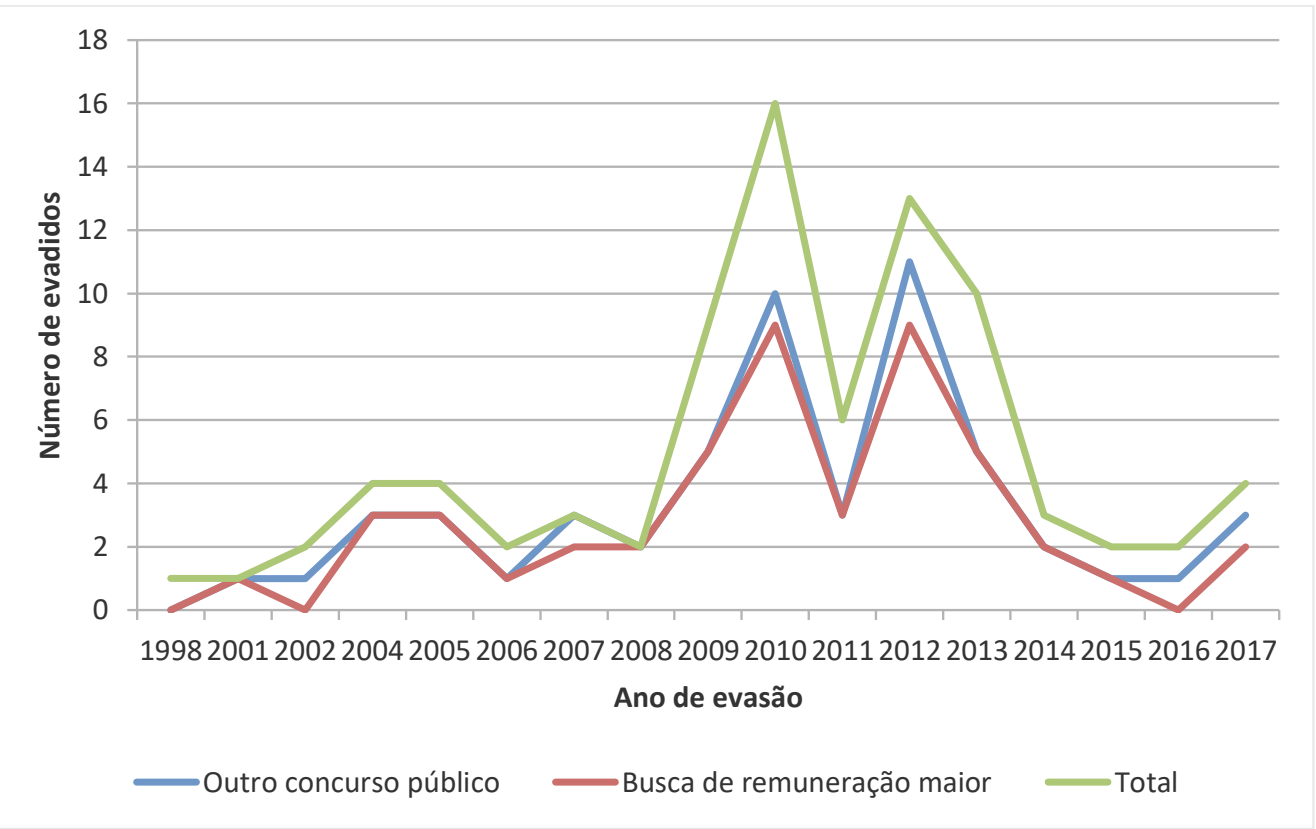

Fonte: Banco de dados da Pesquisa Percursos. Elaboração própria. 
Gráfico 19 | Evadidos da carreira de Especialista em Políticas Públicas e Gestão Governamental (EPPGG) de acordo com o setor em que trabalham atualmente e de acordo com a razão porque abandonaram a carreira

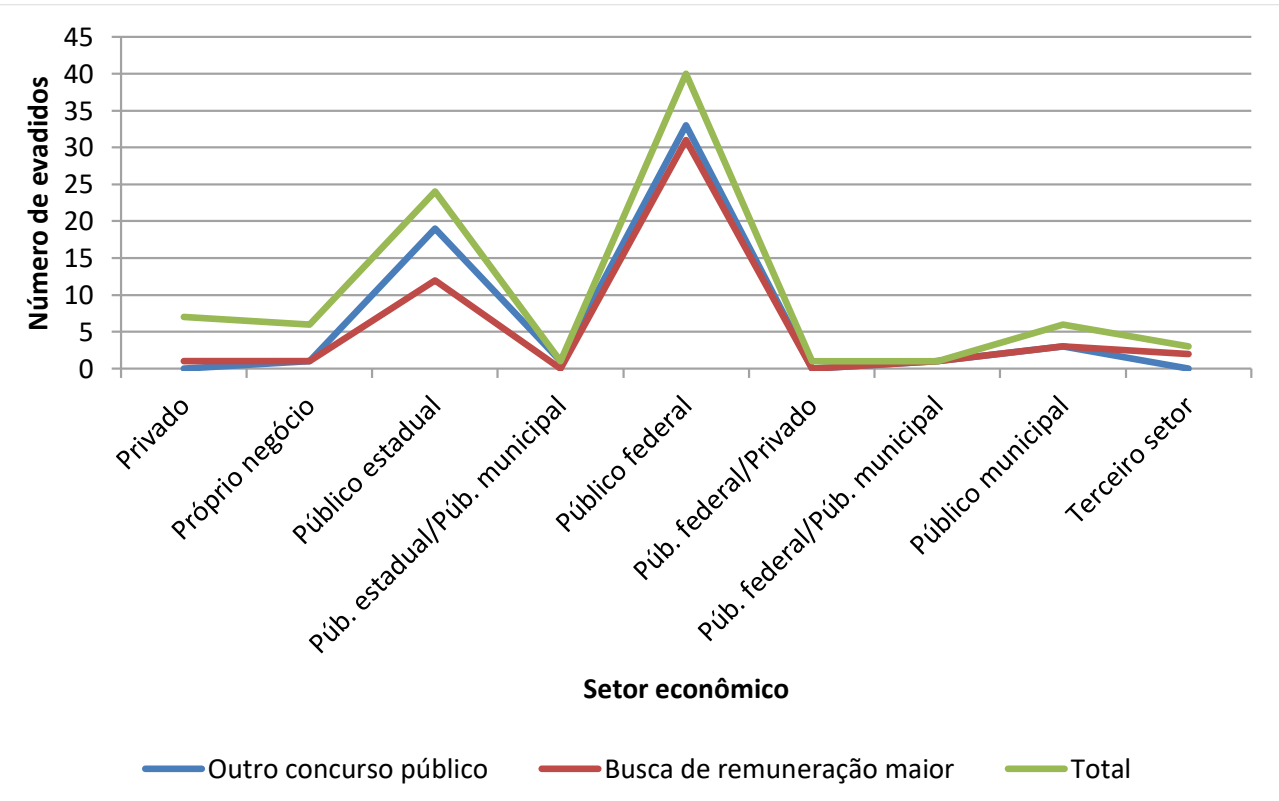

Fonte: Banco de dados da Pesquisa Percursos. Elaboração própria.

Quase seis décimos dos evadidos pesquisados concluíram uma graduação adicional à do Csap. Sete décimos desses o fizeram depois de concluir o Csap (Tabela 8). Mais da metade dessas graduações ocorreram na área do Direito. 13 outros bacharelados foram citados; Engenharia (quatro evadidos); Economia (três); Administração (três) e Ciências Contábeis (três). Mesmo áreas muito distintas da de Administração Pública (como Ciências Biológicas, design ou Medicina) foram mencionadas. Os salários médios citados para essas áreas também se mostraram elevados (Tabela 9). 
Tabela 8 | Evadidos da carreira de Especialista em Políticas Públicas e Gestão Governamental (EPPGG) que concluíram outra graduação

\begin{tabular}{l|rr}
\hline Fez outra graduação? & \multicolumn{1}{|c|}{ Total } & Percentual \\
\hline Não & 38 & 40,43 \\
Sim & 56 & 59,57 \\
\hline Antes do Csap & 6 & 10,71 \\
Durante o Csap & 10 & 17,86 \\
Depois do Csap & 40 & 71,43 \\
\hline
\end{tabular}

Fonte: Banco de dados da Pesquisa Percursos. Elaboração própria.

Tabela 9 | Evadidos da carreira de Especialista em Políticas Públicas e Gestão Governamental (EPPGG) por área das outras graduações concluídas

\begin{tabular}{lrrrr}
\hline Área de outra graduação & Número & Percentual & Salário Médio \\
\hline Administração & 3 & 5,36 & $10.625,00$ \\
Ciência da computação & 1 & 1,79 & $20.000,00$ \\
Ciência política & 1 & 1,79 & $20.000,00$ \\
Ciências biológicas & 1 & 1,79 & $20.000,00$ \\
Ciências Contábeis & 3 & 5,36 & $20.250,00$ \\
Design & 1 & 1,79 & $12.500,00$ \\
Direito & 31 & 55,36 & $18.008,06$ \\
Economia & 3 & 5,36 & $20.000,00$ \\
Engenharia & 4 & 7,14 & $11.125,00$ \\
História & 2 & 3,57 & $16.250,00$ \\
Medicina & 1 & 1,79 & $12.500,00$ \\
Psicologia & 1 & 1,79 & $26.000,00$ \\
Relações internacionais & 2 & 3,57 & $19.250,00$ \\
Sitemas de Informação & 1 & 1,79 & $12.500,00$ \\
Não informado & 1 & 1,79 & - \\
\hline
\end{tabular}

Fonte: Banco de dados da Pesquisa Percursos. Elaboração própria.

Entre os evadidos que cursaram Direito, a grande maioria (58\%) foi absorvida pelo setor público federal. Pouco mais de um quarto (26\%) estão em outra carreira no setor público estadual. Somente $10 \%$ desses foram trabalhar no setor privado (Gráfico 20). 
Gráfico 20 | Proporção de evadidos da carreira de Especialista em Políticas Públicas e Gestão Governamental (EPPGG) que também cursaram Direito pelo atual setor de atuação

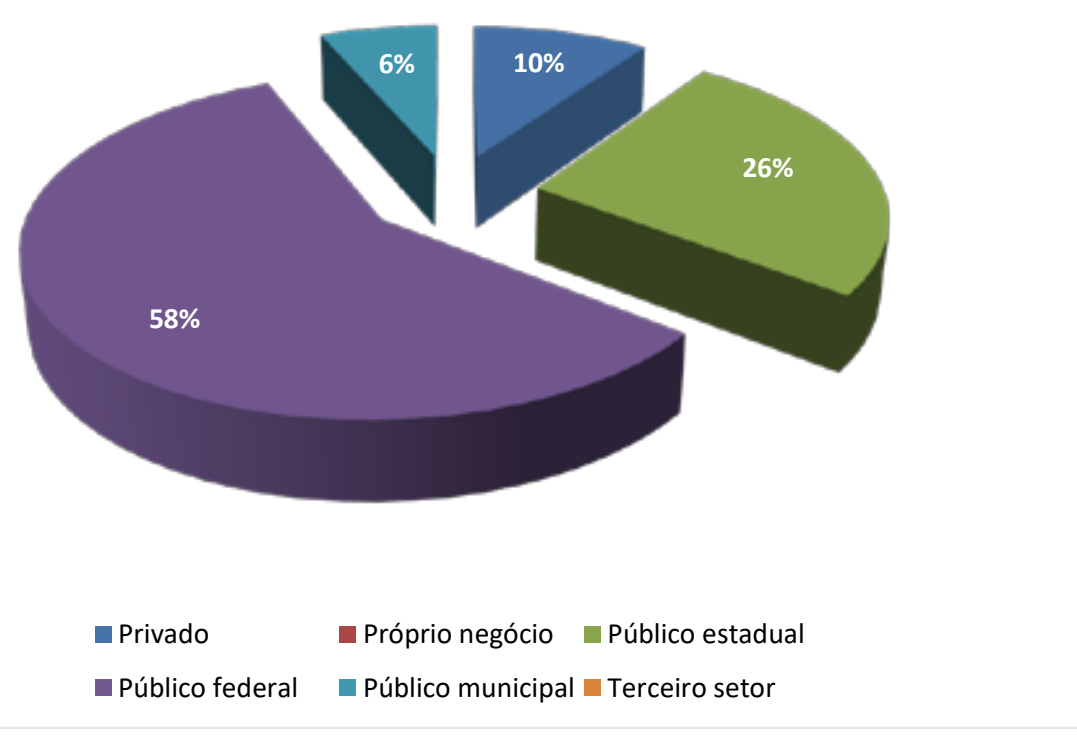

Fonte: Banco de dados da Pesquisa Percursos. Elaboração própria.

Planejamento e avaliação foram as atividades exercidas por 55\% dos evadidos no Estado (enquanto EPPGG), seguidas por modernização da gestão (35\%) e administração financeira e orçamentária (27\%). Menos de um décimo dos evadidos exerceram as outras atividades típicas da carreira. A distribuição dessas atividades não parece apresentar padrão relativo à atual renda aferida pelos evadidos (Tabela 10). 
Tabela 10 | Distribuição percentual dos evadidos da carreira de Especialista em Políticas Públicas e Gestão Governamental (EPPGG) de acordo com as atividades exercidas enquanto EPPGG

\begin{tabular}{|c|c|c|c|c|c|c|c|c|}
\hline Atividades & $\begin{array}{c}\text { Inferior a } \\
\mathrm{R} \$ 3000\end{array}$ & \begin{tabular}{|c|} 
Entre \\
$\mathrm{R} \$ 3001$ e \\
$\mathrm{R} \$ 5000$ \\
\end{tabular} & $\begin{array}{c}\text { Entre } \\
\mathrm{R} \$ 5001 \mathrm{e} \\
\mathrm{R} \$ 7500\end{array}$ & \begin{tabular}{|c|} 
Entre \\
$\mathrm{R} \$ 7501 \mathrm{e}$ \\
$\mathrm{R} \$ 10000$ \\
\end{tabular} & \begin{tabular}{|c|} 
Entre \\
$\mathrm{R} \$ 10001 \mathrm{e}$ \\
$\mathrm{R} \$ 15000$ \\
\end{tabular} & \begin{tabular}{|c|} 
Entre \\
$15001 \mathrm{e}$ \\
$\mathrm{R} \$ \$ 20000$ \\
\end{tabular} & $\begin{array}{c}\text { Acima de } \\
25001\end{array}$ & Total \\
\hline Planejamento e avaliação & 100,00 & 50,00 & 57,14 & 62,50 & 52,17 & 57,58 & 50,00 & 55,43 \\
\hline $\begin{array}{l}\text { Administração financeira e } \\
\text { orçamentária }\end{array}$ & 0,00 & 0,00 & 42,86 & 0,00 & 13,04 & 45,45 & 25,00 & 27,17 \\
\hline Modernização da gestão & 0,00 & 75,00 & 28,57 & 37,50 & 47,83 & 27,27 & 25,00 & 34,78 \\
\hline Recursos humanos & 0,00 & 0,00 & 0,00 & 0,00 & 4,35 & 12,12 & 12,50 & 7,61 \\
\hline Racionalização de processos & 0,00 & 0,00 & 0,00 & 0,00 & 17,39 & 9,09 & 0,00 & 7,61 \\
\hline Recursos materiais & 0,00 & 0,00 & 0,00 & 12,50 & 0,00 & 6,06 & 6,25 & 4,35 \\
\hline Gestão e tecnologia da & & & & & & & & \\
\hline informação & 0,00 & 50,00 & 0,00 & 0,00 & 13,04 & 9,09 & 6,25 & 9,78 \\
\hline $\begin{array}{l}\text { Recursos logísticos, humanos } \\
\text { e administração patrimonial }\end{array}$ & 0,00 & 0,00 & 0,00 & 0,00 & 0,00 & 9,09 & 6,25 & 4,35 \\
\hline Administração patrimonial & 0,00 & 0,00 & 0,00 & 0,00 & 0,00 & 6,06 & 6,25 & 3,26 \\
\hline Políticas públicas & 0,00 & 0,00 & 28,57 & 0,00 & 17,39 & 6,25 & 6,25 & 9,89 \\
\hline
\end{tabular}

Fonte: Banco de dados da Pesquisa Percursos. Elaboração própria.

Nota: O evadido pode ter exercido mais de uma atividade durante sua carreira de EPPGG. Daí que a soma desses valores não é $100 \%$.

A "melhoria da carreira" é o único motivo que levaria muitas pessoas a reingressar na carreira (isso foi citado por 36 pessoas - 20 homens e 16 mulheres). Somente cinco citaram como possível razão para isso estarem desempregados (três homens e duas mulheres) e apenas oito apontaram a piora do mercado de trabalho em outras áreas (quatro homens e quatro mulheres).

Como possíveis razões que os levam a não querer reingressar na carreira, 34 (18 homens e 16 mulheres) citaram a necessidade de se prestar um novo concurso público, 31 (19 homens e 12 mulheres) apontaram a perda de prestígio da carreira no Estado e 22 (oito homens e 14 mulheres) mencionaram a possibilidade de se trabalhar no interior do Estado.

A maioria dos evadidos (tanto total quanto aqueles que declararam ter abandonado a carreira devido a outro concurso público ou à busca de remuneração maior) o fez entre as idades de 24 e 29 anos (Gráfico 21). Ou seja, a evasão tende a ocorrer nas idades iniciais da vida laboral do servidor. 
Gráfico 21 | Evadidos da carreira de Especialista em Políticas Públicas e Gestão Governamental (EPPGG) de acordo com a idade na época da desistência com a motivação apontada para o abandono e total

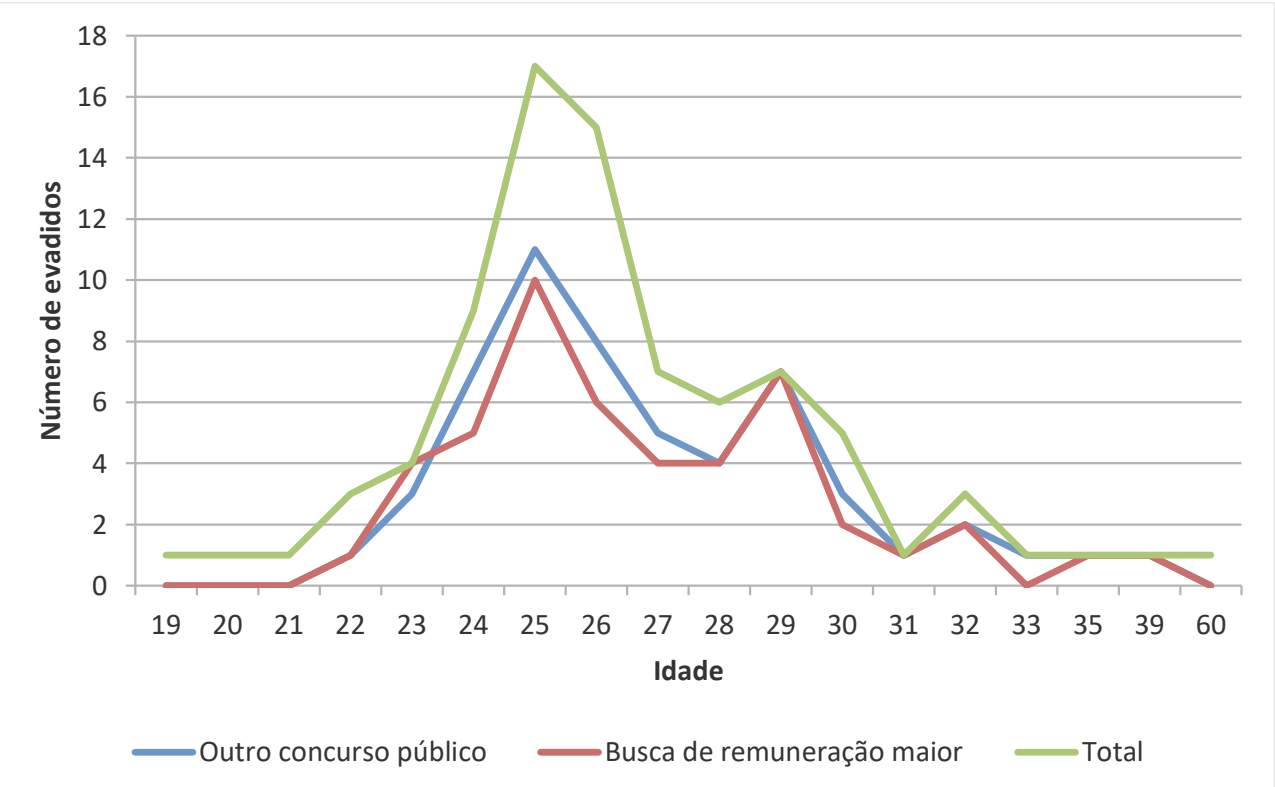

Fonte: Banco de dados da Pesquisa Percursos. Elaboração própria.

\section{Conclusão}

O objetivo principal deste artigo foi analisar a evasão na carreira dos Especialistas em Políticas Públicas e Gestão Governamental no Estado de Minas Gerais. Esta análise revela que o pico das evasões (de acordo com a amostra analisada) ocorreu em 2010 (tanto total quanto homens), seguido de 2012 (pico de saída das mulheres). A melhoria da carreira (dos rendimentos, basicamente) pode explicar esse processo (entre aqueles que se arrependeram da evasão, é grande o percentual que aponta a reestruturação da carreira como motivo de arrependimento). Ou seja, carreiras piores implicam em maiores taxas de evasão e vice-versa. Isso corroboraria os resultados encontrados por Klein e Mascarenhas (2016). No caso mineiro, Andrade (2011) já havia apontado que o principal problema seria a baixa remuneração da carreira, o que foi resolvido. 
A evasão, em sua maioria, ocorreu após o fim do estágio probatório, indicando também que a necessidade de se ressarcir o Estado é fator importante na permanência do servidor em sua carreira. Cruz (2005) também constatou que o momento preponderante para a evasão foi após o fim do estágio probatório (quando finda a obrigatoriedade de ressarcimento ao Estado). A confirmação da insatisfação com a carreira (ou seja, o servidor espera para confirmar sua insatisfação, minimizando arrependimentos) também pode ser fator relevante. A cultura do serviço público, as decisões de alocação menos técnicas que o desejável, e a compensação salarial vinculada ao desempenho de cargos de chefia também foram apontados como fatores que contribuíram para a decisão de evadir nos resultados encontrados por Cruz (2005).

Servidores tendem a evadir quando são mais jovens. A maioria das evasões ocorre quando o servidor tem entre 24 e 29 anos (e isso é observado tanto para o total quanto para cada subgrupo distinto), corroborando os estudos citados anteriormente. Essa é a idade em que os servidores apresentam de dois a quatro anos de experiência enquanto EPPGG. Ou seja, tal qual os estudos de Bright (2008) e Moynihan, Landuyt (2008), quanto maior a idade e o tempo de experiência do servidor, menor a tendência desse de se evadir.

A evasão quando ocorre é definitiva, ou seja, somente uma pequena parte dos evadidos buscou uma licença temporária antes de se evadir. Menos de um quinto se arrependeu de tê-lo feito (esses apresentaram salário médio menor que daqueles que não se arrependeram). A imensa maioria se realoca no próprio setor público (pouco menos da metade no nível federal, enquanto pouco mais de um quarto no próprio nível estadual). É possível, aqui também, que exista um viés de seleção. Os servidores que tiraram licença temporária pensando em se evadir não o fizeram - a experiência da licença temporária não Ihes garantiu satisfação suficiente para que abandonassem a carreira.

Os salários médios dos evadidos apresenta nível bem maior que os valores médios observados para quem está na carreira. Dado que a grande maioria dos evadidos se realocou no próprio setor público, é natural esperar que esses tenham buscado carreiras melhores que a dos EPPGG (corroborando, portanto, a ideia de que a melhoria da carreira fez com que as taxas de evasão caíssem). Entretanto, a experiência média de quem ficou na carreira é bem menor que aquela de quem saiu. Ganhos relativos a essa experiência poderiam explicar parte dessa diferença. 
Por fim, pode ter ocorrido viés de seleção na amostra obtida. É possível que somente aqueles que conseguiram se realocar em boas condições tenham tido incentivos para responder ao questionário, explicando essa diferença. Apesar dos salários médios de homens e mulheres serem similares (o primeiro é ligeiramente superior ao segundo), as distribuições salariais por gênero são diferentes. É muito maior a proporção de homens nas faixas salariais mais altas (também ocorre nas mais baixas). Ou seja, as mulheres têm maior facilidade de realocação (não ficam nas faixas salariais mais baixas), mas apresentam um limite de crescimento profissional - existe um "teto de vidro" em suas carreiras profissionais pós-evasão. Esses resultados não são observados na distribuição por etnia dos evadidos.

Todos aqueles que abandonaram a carreira antes da posse indicaram ter sido aprovados em outro concurso público (metade desses, curiosamente, apontou também uma insatisfação com a carreira pública).

Seis décimos dos evadidos concluíram uma graduação adicional. Metade deles na área do Direito - esse grupo apresentou salário médio maior que aquele da amostra como um todo. Desse grupo (que também fez a graduação em Direito), mais da metade se realocou no setor público federal. Pouco mais de um quarto buscou uma nova carreira em nível estadual. Somente um décimo deles foi para o setor privado. A existência de motivação relativa ao serviço público (PSM - Public Service Motivation), citada anteriormente, pode explicar isso. Os servidores, mesmo os evadidos, apresentam uma satisfação por trabalhar no serviço público. Mesmo aqueles que se transferiram para a iniciativa privada declararam sua insatisfação com a incapacidade do Estado de, efetivamente, implementar políticas públicas que melhorassem o nível de vida das pessoas. Ou seja, a evasão não tem se dado por uma menor preocupação em servir à população, mas com a decepção com a capacidade do Estado de fazê-lo, o que também corrobora os resultados da literatura citada.

Também foi impossível fazer qualquer conclusão sobre o impacto de diferentes sistemas de aposentadoria sobre as taxas de evasão. Não só uma grande parcela desses servidores continuou no setor público, como a evasão ocorreu logo no início da vida profissional dos servidores (o que minimiza as perdas referentes à evasão). É possível que no antigo sistema de aposentadoria do setor público (em que não existisse um teto para o 
valor das aposentadorias), a taxa de evasão diminuísse com o tempo de serviço (ou seja, quanto mais perto da aposentadoria o servidor estiver) devido à perda com a migração para sistema que apresentasse um teto. Essa hipótese também não pôde ser testada.

Por fim, também não foram obtidos resultados relativos à relação entre a diversidade existente nos diferentes órgãos públicos (ou seja, na experiência pessoal dos evadidos) e a taxa de evasão observada. Nenhum evadido citou, como possível causa para a evasão ou como possível razão para não se evadirem as respostas relativas à diversidade. Isso, porém, não implica que essas não sejam importantes. Diversos estudos (como os citados) mostram isso. Mas isso requer novos estudos.

Vale lembrar que, embora estudos específicos sobre a evasão na carreira de EPPGG em outras unidades da federação não tenham sido encontrados, e que no caso de Minas Gerais a remuneração apareça como a principal razão, a correlação entre motivação, satisfação no trabalho e remuneração está sempre presente para nortear possíveis causas de evasão.

\section{Referências bibliográficas}

AlmeIDA, Lindijane S. B.; Rodrigues, Maria Isabel; SILVeIRA, Raquel Maria C. Ensino no campo de políticas públicas: o caso dos cursos da Universidade Federal do Rio Grande do Norte (UFRN) e da Escola de Governo da Fundação João Pinheiro (EG/FJP). Nau Social, v. 9, n. 17, p. 103-117, abr.2019.

ANDRADE, Nahissa H. Seino. A introdução dos especialistas em políticas públicas e gestão governamental na administração pública brasileira: análise comparativa da carreira nas esferas estadual e federal. Congresso Consad de Gestão Pública, 4., 2011, Brasília. Anais [...]. Brasília: Consad, 2011.

BRIGHT, Leonard. Does public service motivation really make a difference on the job satisfaction and turnover intentions of public employees? The American Review of Public Administration, $v$. 38, n. 2, p. 149-166, June 2008.

CAILLIER, James Gerard. Are teleworkers less likely to report leave intentions in the United States Federal Government than non-teleworkers are? The American Review of Public Administration, v. 43, n. 1, p. 72-88, 2013.

$\mathrm{CHOI}$, Sungjoo. Diversity in the US Federal Government: diversity management and employee turnover in federal agencies. Journal of Public Administration Research and Theory, v. 19, n. 3, p. 603-630, July 2009. 
Clark, Robert L.; Hanson, Emma; MorRILL, Melinda S.; PATHAK, Aditi. Supplemental plan offerings and retirement saving choices: an analysis of North Carolina School Districts (n. 21382). National Bureau of Economic Research Working Paper, v. 21382, 2015.

Coelho, Fernando S.; OlensCKI, Antônio R. B.; Celso, Rafael P. Da letargia ao realento: notas sobre o ensino de graduação em administração pública no Brasil no entremeio da crise do Estado e da redemocratização no país (1983-94). Revista de Administração Pública, v. 45, n. 6, p. 1707-1732, nov./dez. 2011.

CRUz, Rútila Maria Soares Gazzinelli. A evasão dos administradores públicos em Minas Gerais. 2005. Dissertação (Mestrado em Administração Pública) - Escola de Governo, Fundação João Pinheiro, Belo Horizonte, 2005.

DESANTIS, V. S.; DURST, S. L. Comparing job satisfaction among public and private sector employees. The American Review of Public Administration, v. 3, n. 26, p. 327-343, 1996.

ELLICKSON, Mark C. Determinants of job satisfaction of municipal government employees. Public personnel management, v. 31, n. 3, p. 343-359, Fall 2002.

ELY, Robin J. A field study of group diversity, participation in diversity education programs, and performance. Journal of Organizational Behavior, 25, p.755-80, 2004.

FARIAS, Pedro C. L.; GAETANI, Francisco. A política de recursos humanos e a profissionalização da administração pública no Brasil do século XXI: um balanço provisório. Congreso Internacional del CLAD sobre Reforma del Estado y Administración Pública, 7, 2002, Lisboa. Anais [...]. Lisboa: CLAD, 2002.

FUNDAÇÃo JoÃo PINHEIRO. Histórias de gestores governamentais: formação e experiência profissional de egressos do curso de Administração Pública (Csap) da Fundação João Pinheiro (FJP). Belo Horizonte: FJP, 2019.

GADJENDRAN, Ravi Shanker; HARRISON, Davi A. The good, the bad, and the unknown about telecommuting: meta-analysis of psychological mediators and individual consequences. Journal of Applied Psychology, v. 92, n. 6, p. 1524-1541, Nov. 2007.

Goldhaber, Dan; Grout, Cyrus; Holden, Kris. Pension structure and employee turnover: evidence from a large public pension system. Washington: Calder, Sept. 2015. (Calder working paper, 142).

GrISSOM, Jason A.; NiCHOLSON-CROTTY, Jill; KEISER, Lael. Does my boss's gender matter? Explaining job satisfaction and employee turnover in the public sector. Journal of Public Administration Research and Theory Advance, v. 22, n. 4, p. 649-673, Oct. 2012.

GrISSON, Jason A.; VIANO, Samantha L.; SELIN, Jennifer L. Understanding employee turnover in the public sector: insights from research on teacher mobility. Public Administration Review, v. 76, is. 2, p. 241-251, mar./apr. 2016.

IPPOLITO, Richard A. Stayers as "Workers" and "Savers": toward reconciling the pension-quit literature. Journal of Human Resources, v. 37, n. 2, p. 275-308, 2002.

JACKSON, Susan E.; JOSHI, Aparna R. Diversity in social context: a multi-attribute, multilevel analysis of team diversity and sales performance. Journal of Organizational Behavior, v. 25, p. 675-702, 2004. 
JACKSON, Susan E.; JOSHI, Aparna R.; ERHARDT, Niclas L. Recent research on team and organizational diversity: SWOT analysis and implications. Journal of Management, v. 29, p. 80130, 2003.

KAMDRON, Tiiu. Work motivation and job satisfaction of Estonian higher officials. International Journal of Public Administration, v.28, n. 13-14, p.1211-1240, 2005.

KLEIN, Fábio Alvim; MASCARENHAS, André O. Motivação, satisfação profissional e evasão no setor público: o caso da carreira de especialistas em políticas públicas e gestão governamental. Revista de Administação Pública, v. 50, n. 1, p. 17-39, jan./fev. 2016.

MohAmmed, Susan; ANGELL, Linda C. Surface- and deep-level diversity in workgroups: examining the moderating effects of team orientation and team process on relationship conflict. Journal of Organizational Behavior, v. 25, p.1015-1039, 2004.

MOYNIHAN, D. P.; LANDUYT, N. Explaining turnover intention in state government: examining the roles of gender, life cycle, and loyalty. Review of Public Personnel Administration, v. 28, n. 2, p. 120-143, mar. 2008.

MOYNIHAN, D. P.; PANDEY, S. K. The role of organizations in fostering public service motivation. Public Administration Review, v. 67, p. 40-53, 2007.

NAFF, Katherine C.; CRUM, John. Working for America: does public service motivation make a difference? Review of Public Personnel Administration, v. 19, n. 4, p. 5-15, 1999.

O’Reilly, Charles A.; CALDWelL, David F.; BARnetT, William P. Work group demography, social integration, and turnover. Administrative Science Quarterly, v. 34, n. 1, p. 21-37, 1989.

OliveIRA, Kamila Pagel de. Gestão de recursos humanos no estado de Minas Gerais: retenção de pessoas no cargo de Especialista em Políticas Públicas e Gestão Governamental. 2009. Dissertação (Mestrado em Administração) - Centro de Pós-Graduação e Pesquisas em Administração, Faculdade de Ciências Econômicas, Universidade Federal de Minas Gerais, Belo Horizonte, 2009.

Oliveira, Kamila Pagel de; Ckagnazaroff, Ivan Beck; Silveira, Mauro César; Moraes, Carlos Eduardo Simões. Retenção de pessoas no setor público mineiro: o caso dos Especialistas em Políticas Públicas e Gestão Governamental. Revista de Carreiras e Pessoas, v. 2, n. 3, p. 46-64, 2012.

Pelled, Lisa H.; EISENhARDT, Kathleen M.; XIN, Katherine R. Exploring the black box: an analysis of work group diversity, conflict, and performance. Administrative Science Quarterly, v. 44, n. 1, p. $1-28,1999$.

PERRY, J. Measuring public service motivation: an assessment of construct reliability and validity. Journal of Public Administration Research and Theory, v. 6, n. 1, p. 5-22, 1996.

SACKETT, Paul R.; DUBOIS, Cathy L. Z. Rater-ratee race effects on performance evaluation: challenging meta-analytic conclusion. Journal of Applied Psychology, v. 76, n. 6, p. 873-877, 1991.

SACKETT, Paul R.; DuboIS, Cathy L. Z.; NOE, Ann W. Tokenism in performance evaluation: the effects of work group representation on male-female and white-black differences in performance ratings. Journal of Applied Psychology, v. 76, n. 2, p. 263-267, 1991. 
SCOTT, P. G.; PANDEY, S. K. Red tape and public service motivation: findings from a national survey of managers in state health and human services agencies. Review of Public Personnel Administration, v. 25, n. 2, p. 155-180, 2005.

SELDEN, S. C.; MoYNIHAN, D. P. A model of voluntary turnover in state government. Review of Public Personnel Administration, v. 20, n. 2, p. 63-74, 2000.

TsUI, Anne S.; EgAN, Terri D.; O’REILly, Charles A. Being different: relational demography and organizational attachment. Administrative Science Quarterly, v. 37, n. 4, p. 549-579, 1992.

WAgneR, Gary W.; Pfeffer, Jeffrey; O'ReILly, Charles A. Organizational demography and turnover in top-management groups. Administrative Science Quarterly, v. 29, n. 1, p. 74-92, 1984.

\section{Rutila Maria Soares Gazzinelli Cruz}

(D) https://orcid.org/0000-0001-7407-3489

Mestre em Administração Pública pela Fundação João Pinheiro (2005). Bacharel em Ciências Econômicas e Administração pela Pontifícia Universidade Católica de Minas Gerais. Pesquisador na Fundação João Pinheiro atuando na área de Políticas Públicas.

E-mail: rutila.gazzinelli@fjp.mg.gov.br

\section{Claudio Burian Wanderley}

(D) https://orcid.org/0000-0002-4559-176X

Doutor em Teoria Econômica pela Escola de Pós-Graduação em Economia (EPGE) da Fundação Getúlio Vargas. Mestre em Economia pela Universidade de São Paulo. Bacharel em Economia pela Universidade Federal de Minas Gerais. Pesquisador pleno da Fundação João Pinheiro e Professor adjunto III da Pontifícia Universidade Católica de Minas Gerais.

E-mail: claudio.burian@fjp.mg.gov.br 